\title{
ON THE COMPARATIVE ANATOMY AND FUNCTION OF THE NASAL TRACT IN ODONTOCETES (MAMMALIA, CETACEA)
}

\author{
by \\ E. J. SCHENKKAN \\ Zoological Laboratory, University of Amsterdam, The Netherlands
}

\begin{abstract}
In the study of phonation in odontocete cetaceans and particularly that of echolocation by means of sonar, a great number of conflicting hypotheses have been advanced regarding the correlation of sound production with the many anatomical features that are to be found in the upper respiratory tract.

The present paper follows a new approach via finding out if, and how, the various structures had evolued from the condition in the relatively primitive River Dolphins to the more highly specialized pelagic species.

An introduction to the general anatomy of the upper respiratory tract is given, relating it to work previously published on this subject.

A historical review of the various theories of sound production establishes the essence of the existing controversies.

One or more specimens of a representative number of species from each family have been dissected and described briefly.

The species have been arranged approximately in a series of phylogenetic stages of the upper respiratory tract.

It was found that there was a gradual diminution in relative size of the more superficial air chambers and an increase in the relative volume of the deeper, premaxillary diverticula.

This seemed to indicate that the site of sound production is situated in the lower posterior narial tract, and that the sound is transmitted by the bones forming the rostrum.

Radiographic examination of the bones of the rostrum of skulls in various stages of development was undertaken to ascertain the most favourable sound paths.

It was concluded that the sonar pulses at least were produced by the larynx, which does not vary greatly in structure throughout the suborder.
\end{abstract}

\section{INTRODUCTION}

In recent years there has been an increasing interest by zoologists, anatomists, and physiologists, in sounds emitted by cetaceans, some of which have a communicative meaning, whilst others have been shown to be used for sound navigation and ranging or "sonar". One of the problems hitherto unresolved has been that of as- certaining the precise mechanism by which these sounds are emitted. Theories appear to fall into two schools of thought:

1. those who maintain that sound is produced above the level of the rostrum amongst the various pneumatic chambers that are found in the upper respiratory tract,

2. those who believe the sounds to be produced below the level of the rostrum in the region of the nasopharynx and more specifically by the larynx and glottis.

Unfortunately, due to the availability of small cetaceans in dolphinaria, most of the experimental work has been carried out on a few rather specialized species, in particular the Bottle-nosed Dolphin Tursiops truncatus (Montagu, 1821). However, it seemed to me that there was considerable interfamilial and intergeneric variation in the structure of the upper respiratory tract throughout the entire suborder Odontoceti and it was difficult to see how a correct interpretation of the phonatory mechanisms could be arrived at without a thorough morphological examination of these variations.

In view of the conflicting theories on phonation, it was decided to examine the anatomy of the nasal region and to test the various hypotheses on sonar and general phonation in the Odontoceti. The respiratory mechanisms of the following species will be briefly described:

PLATANISTIDAE, represented by Pontoporia blainvillei (Gervais \& d'Orbigny, 1844) described by Schenkkan, 1972),

HYPEROODONTIDAE: by Mesoplodon bidens, (Sowerby, 1825) and Hyperoodon ampullatus (Forster, 1776),

PHYSETERIDAE: by Kogia simus (Owen, 1866), $K$. breviceps (de Blainville, 1838), and Physeter macrocephalus Linnaeus, 1758 (described by Schenkkan \& Purves, 1973), 
MONODONTIDAE: by Monodon monoceros Linnaeus, 1758 (described by Huber, 1934), PHOCOENIDAE: by Phocoena phocoena (Linnaeus, 1758),

DELPHINIDAE, represented by:

the Cephalorhynchinae: Cephalorhynchus hectori (van Beneden, 1873),

the Lissodelphinae: Lissodelphis borealis (Peale, 1848),

the Globicephalinae: Orcinus orca (Linnaeus, 1758),

the Delphininae:

Lagenorhynchus albirostris (Gray, 1846), L. acutus (Gray, 1828), L. obliquidens Gill, 1865. and $L$. obscurus (Gray, 1828),

Tursiops truncatus (Montagu, 1821),

Stenella coeruleoalba (Meyen, 1833), S. frontalis

(G. Cuvier, 1829), and S. longirostris (Gray, 1828),

Delphinus delphis Linnaeus, 1758 ,

STENIDAE, represented by Sotalia guianensis

(P. J. van Beneden, 1864).

\section{HISTORICAL AND ANATOMICAL DATA}

It has been known since the time of the ancient Greeks that cetaceans can produce and perceive sounds. Noises made by smashing wooden poles or oars on the surface of the water or by clashing stones together below the surface are often used by fishermen to frighten dolphins and to drive them in a certain direction (Aristotle, 384322 B.C.; Dudok van Heel, 1962; Dawbin, 1967).

Fraser (1947) stated that about a hundred Common Dolphins swimming near the R.V. "Atlantide" dashed away at high speed at the moment the ship's ultrasonic echo-sounder was switched on. Similar experiences were found with asdic employed by whale-catchers. Mc Bride (1956) noticed that Bottle-nosed Dolphins could recognize and avoid a net of fine mesh but could not avoid nets with relatively larger mesh. He suggested that echolocation, such as had been discovered in bats, was being used by the dolphins and concluded that no echoes were returned from the nets with larger mesh.

Pierce \& Griffin (1938) found that bats produced ultrasonic sounds of about $50 \mathrm{kHz}$ consisting of short pulses or clicks which could only be detected when a microphone was placed exactly in front of the bat's mouth. Dijkgraaf (1943) found components in the phonation consisting of pulse trains which he called "rattling sounds". He stated that the rate of emission of the clicks increased to a buzzing tone when the bat was confronted with orientation difficulties or immediately before it reached an object. After much experimentation he concluded that this rattling, which he could hear with the unaided ear, was associated with the orientation of the animal.

Kellogg \& Kohler (1952) were the first to discover that odontocetes could produce sounds up to $80 \mathrm{kHz}$ and supposed that these sounds might have a function in echolocation, since the character of the emitted sounds resembled those emitted by bats as observed by Dijkgraaf (1943, 1947), Griffin (1946, 1950), and Griffin \& Calambos (1940).

Schevill \& Lawrence (1953) stated that dolphins were sensitive to sounds of over $120 \mathrm{kHz}$ and found some evidence for echolocation.

Kellogg, Kohler \& Morris (1953) carried out detailed experiments with Tursiops truncatus, eliminating all visual and chemical stimuli. They produced very convincing evidence that echolocation was being used. The matter was finally resolved by Norris et al. (1961) who found that, in spite of blindfolding a Bottle-nosed Dolphin, it retained the ability to find food, to avoid obstacles and even to differentiate between morsels of fish of different species. They found that the repetition frequency of emitted pulses was considerably lower when the animal was at some distance from the target than when it was at close range. It was also observed that the animal made lateral head movements whilst approaching the target.

Since then an increasing number of species have been found to also emit sounds. The larger baleen whales emit a great variety of moans, croaks, whistles, and other cries, all generally of under $400 \mathrm{~Hz}$. (Schevill, Backus \& Hersey, 1962; Schevill \& Watkins, 1962; Eberhardt \& Evans, 1962; Watkins, 1966). A large number of sonic and ultrasonic sounds have been reconded from the smaller odontocetes (Evans \& Prescott, 1962; Mizue, Nishiwaki \& Takemura, 1971; Mizue, Takemura \& Nakasai, 1968, 1969; Caldwell, Caldwell \& Evans, 1966; Caldwell, Prescott \& Caldwell, 1966; and Vincent, 1959, 1960).

In most terrestrial mammals the source of sound is located in the larynx where air is passed between vocal cords or between other laryngeal structures, thus setting both the air and laryngeal structures into vibration. Sounds made in 
this way are easily transmitted to the air-filled cavities of the mouth and thence to the surrounding air, since there is no large change in density in the sound path. It has been established that in cetaceans there are no vocal cords, but other structures such as thyroarytenoid folds and aryepiglottic folds like those found in many terrestrial mammals, are known to be present and could subserve the function of phonation. Airborn sounds as emitted by terrestrial mammals can hardly be transmitted to the surrounding water, since whenever sound vibrations pass from a gaseous to a solid or liquid medium, there is over 99\% reflection of energy at the interface. For this reason, special modifications of the sound emitting organs would be required to facilitate the transmission of the laryngeal vibrations to the surrounding water. Lawrence \& Schevill (1956) suggested that there might be another structure, apart from the larynx, responsible for sound production. Norris et al. (1961) concluded, from the anatomical work of Lawrence \& Schevill and their own observations with a blindfolded dolphin, that the source of these sounds must be located above the level of the rostrum: i.e. in the complex nasal tract between the bony nares and the blowhole. On the contrary, Lawrence \& Schevill (1956) stated that in their personal opinion the sounds are of laryngeal origin.

Purves (1966) stated that the larynx is very well formed and located for the production of the sounds of high frequency such as used in echolocation, and noticed that the intensity of the sounds emitted by dolphins increased rostrad from the level of the blowhole, being at a maximum at the tip of the snout. Diercks et al. (1971) made similar observations but stated that from their experiments it was clear that the sounds were produced in the region of the nasal plugs. Norris et al. (1961) and Evans \& Prescott (1962) concluded that sounds produced near the diverticula of the nasal tract would be reflected rostrad by the nasal and maxillary bones acting as a parabolic reflector. From here, the sounds would be directed forward where they would enter the "melon", the adipose cushion forming the forehead of most odontocetes. These sounds, they postulated, would also be reflected by the walls of the various air-filled diverticula because of the $99 \%$ reflection due to the air-water interface. Eventually the wave trains would arrive at the melon which would act as an acoustic lens, focussing the sounds to a point in front of the animal. The muscle layers associated with the blowhole would effectuate slight movements and deformations of the melon and thus enable the animal to focus on objects at different distances.

Norris (1964) stated that high pitched sounds could be picked up in a hydrophone only when the tip of the snout of the animal was pointed directly at it, thus contradicting a statement in his previous paper (1961) that a blindfolded animal could only find a piece of fish when it was presented above the level of the rostrum and rostral to the ears.

By studying cineradiographs of the head of a squealing Longsnouted Dolphin (Stenella longirostris), Norris et al. (1971) produced evidence of sound production above the level of the bony nares. In these experiments they observed that during sound production, there was a correlation between the movement of the left nasal plug, and inflation of the premaxillary diverticula. From the fact that during their experiments the animal did not emit clicks, and that the right nasal plug had a larger lateral lip than the left, they concluded that the clicks might be produced by the right nasal plug. The fact, that during phonation the premaxillary diverticula were inflated supported their idea that these diverticula would block the transmission of sounds to the deeper parts of the animal's head.

Occlusion of the nostrils is accomplished in different ways in the two suborders of Cetacea. It is known that the Mysticeti have two external nostrils situated on top of the head that give direct entrance to two separate nasal passages, the walls of which are furnished with interdigitating folds. When the external hydrostatic pressure is raised, the occlusion of the nostrils is increased. The dilation of the nasal passages is caused by active contraction of the well developed layers of the maxillonasal muscle, whilst closure is due to elastic recoil of the various tissues. In the Odontoceti a single blowhole leading into an unpaired vestibule, and thence into a pair of nasopalatine canals, is situated on top of the head. It is generally agreed that in this suborder also, closure is due to elastic recoil of the tissues, and opening to muscular contraction. But, in addition, the blowhole must be sealed by internal pneumatic pressure during the phonatory activity.

In most terrestrial mammals the nostrils are found near the tip of an elongated snout, and are guarded by a pair of elongated nasal bones (fig. $1, B)$. Consequently, by the caudad migration of 


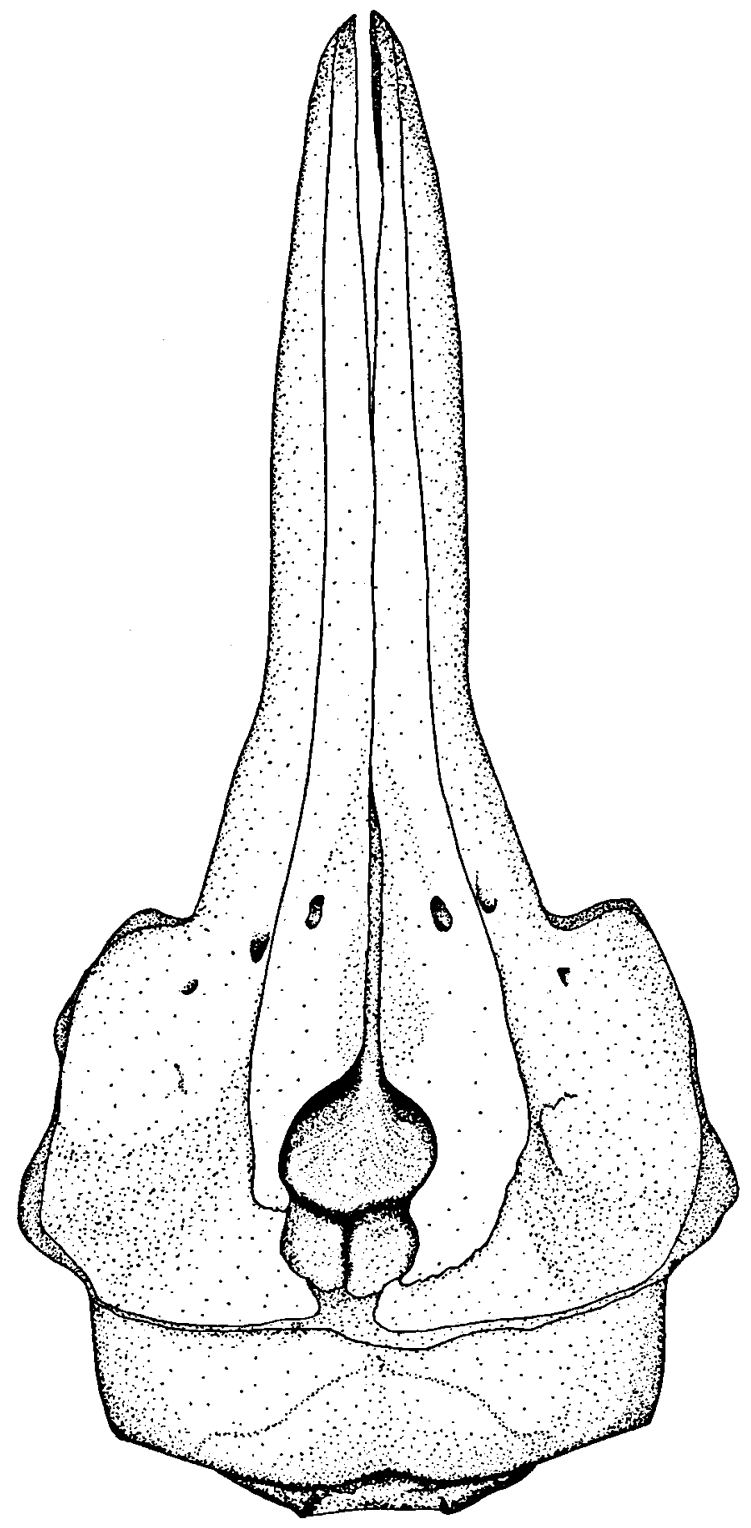

A

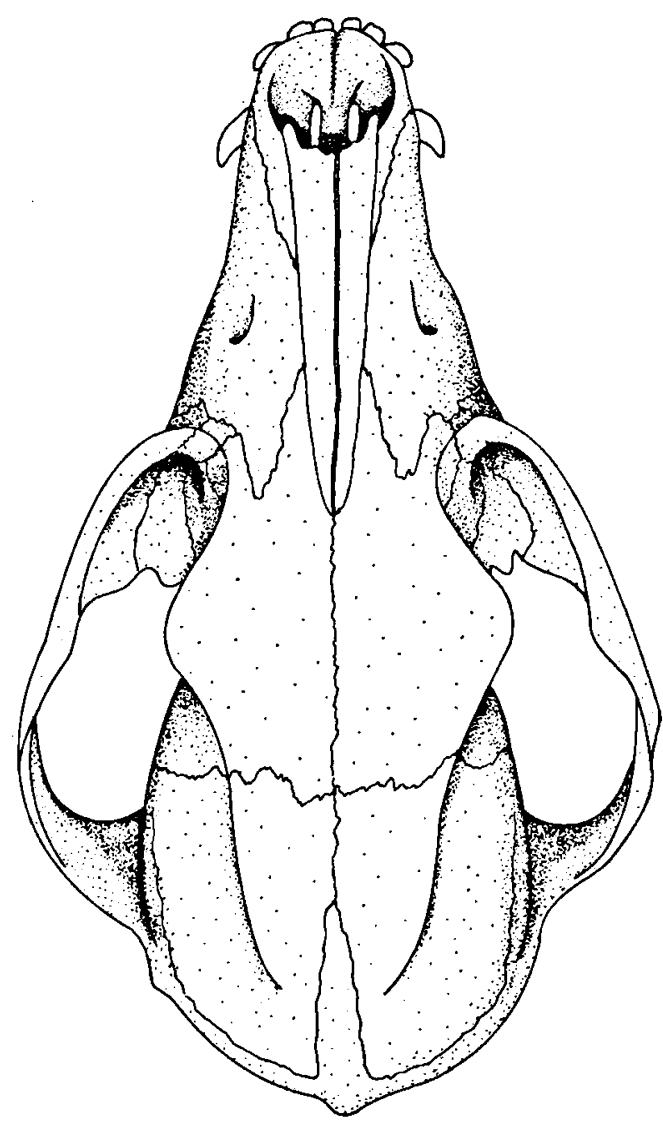

B

Fig. 1. Drawing of the dorsal aspect of the skull of A, a Common Dolphin, B, a dog, showing the relative position of the various bones.

the nostrils in cetaceans during evolution, the skull has undergone special modifications. Most conspicuous of these is the truncation and compression of the nasal bones into a pair of small nodules on the anterior aspect of the frontal bone (fig. 1,A). Meanwhile, both the maxilla and premaxilla have become flattened dorso-ventrally, and much elongated. This elongation has taken place both rostrad and caudad so that the caudal elements shifted over the frontal bones, the latter being almost completely occluded in adult animals. Moreover, the premaxilla and maxilla are considerably expanded laterally in the nasal region. This modification of the maxillary bones provides a large area of attachment for the strongly developed nasal muscles, which in most terrestrial mammals remain restricted to a few elements at the tip of the rostrum.

In the skull of very young odontocetes the caudal outgrowth of the maxillary elements is 


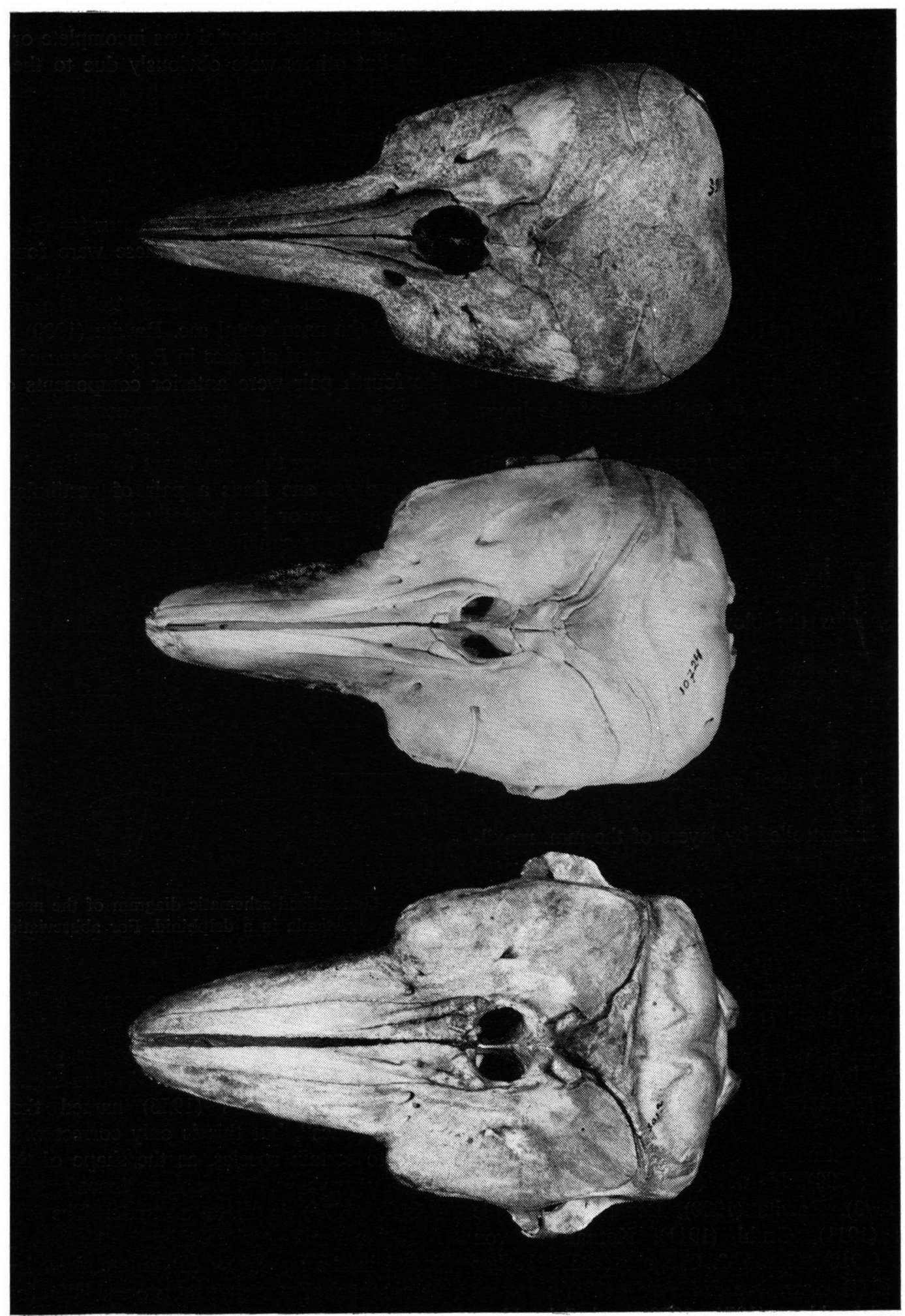

Fig. 2. Series of skulls of Phocoena phocoena demonstrating the caudad migration of the bony nares and the development and caudad growth of the maxillary bones. From top to bottom: the skull of a neonatal, young, and old individual. 
considerably less than in older animals, so that a relatively broad part of the frontal bone is visible on the dorsal aspect of the skull. Comparing skulls of young and older individuals, one can understand the evolutionary trend of the caudad migration of the nasal passage starting from the condition found in the terrestrial mammals (fig. 2). Of course, there are many more differences between the skulls of cetaceans and terrestrial mammals but these are not within the scope of this paper.

In terrestrial mammals, the nostrils, though primarily concerned with respiration, also have an olfactory function. In the Odontoceti, reduction of the olfactory structures is complete and so the only function is that of ventilation of the lungs. In the Mysticeti there are both olfactory lobes in the brain and olfactory conchae in the nostrils though both are relatively small and undifferentiated. In Physeteridae the single blowhole gives entrance to two separate nasal canals of which the left one has a diameter that may be seven times that of the right. Moreover, in Physeter macrocephalus the blowhole is not situated on top of the head near the midline but near the tip of the snout on the left side of the head. This appears to be a secundary characteristic due to the development of the spermaceti organ (Schenkkan \& Purves, 1973). With the exception of Physeter and Kogia, the nasal passages of all odontocetes possess lateral and paired diverticula. The lumen of them is controlled by layers of the mm. maxillonasalis and maxillolabialis which are extremely well developed in all cetaceans.

Murie (1873) stated that "certain layers of blowhole muscle pull the blowhole closed while others open it". This was also Huber's opinion (1934) while Kükenthal (1893), Boenninghaus (1902) and Gruhl (1911) found that closure was due to the elasticity of several tissues and was enhanced by both internal air pressure and external hydrostatic pressure. These authors also found that dilation of the nasal tract was due to muscular contraction.

Tyson (1680), Hunter (1787), Murie (1870 a \& b, 1873), Rawitz (1900), Benham (1901), le Danois (1911), Gruhl (1911), Kernan \& von Schulte (1918), Raven \& Gregory (1933), Huber (1930, 1934), Lawrence \& Schevill (1956), Purves (1966), Schenkkan $(1971,1972)$ and Schenkkan \& Purves (1973) described anatomical aspects of the nasal region of odontocetes. In comparing these descriptions many contradictory points are apparent. Some of these may have been due to the fact that the material was incomplete or damaged but others were obviously due to the great differences amongst the genera and species and a considerable infraspecific variability. Gruhl (1911) described four pairs of air sacs in Delphinus delphis and Tursiops truncatus but only three pairs in Phocoena phocoena. Murie (1870b) described seven air sacs in Grampus rissoanus $(=G$. griseus G. Cuvier, 1812), three of these were found on the left side and four on the right. However, the fourth sac on the right constituted the anterior part of the nasofrontal sac. Rawitz (1900) counted four pairs of air sacs in $\boldsymbol{P}$. phocoena of which the fourth pair were anterior components of the nasofrontal sacs. In most odontocetes it is possible to trace four pairs of air sacs.

On exploring the nasal tract from the blowhole downwards, one finds a pair of vestibular sacs situated more or less laterally to the nasal canal (fig. 3). They can be seen as extensions of the

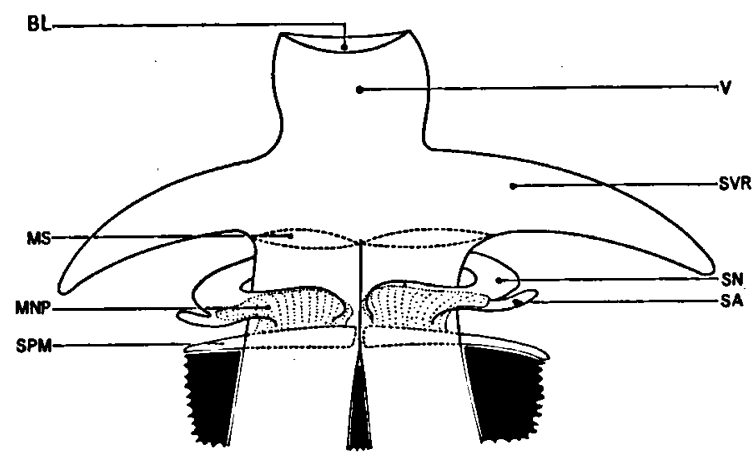

Fig. 3. Generalized schematic diagram of the nasal tract and its diverticula in a delphinid. For abbreviations see page 157 .

vestibule which in some instances is a distended part of the nasal canal just below the blowhole. Deep to the vestibular sacs another pair of air sacs surround the nasal canal in two semicircles. Lawrence \& Schevill (1956) named these as "tubular sacs", but this is only correct when applied to certain species, as the shape of the sacs is not always so. The name "nasofrontal sac" (Murie, 1871) is more accurate. The entrance from the nasal canal to this diverticulum can be found in the caudal or caudo-lateral wall of the nasal canal. Somewhat ventro-caudally to these entrances, apertures can be found leading into a pair of smaller pouches. These were described by Gruhl (1911) as "Blindsäcke" and by Burne (1952) as "subsidiary sacs". Lawrence \& Schevill 
(1956) were of the opinion that these sacs connect the inferior and superior parts of the nasal tract, and consequently referred to them as "connecting sacs". Since considerable variation exists in the development of these sacs, from being very large in some species to non-existent in others, they were referred to by Schenkkan (1971) as "accessory sacs".

Just below, and mesial to, the level of the accessory sacs, a pair of bulbous processes of the anterior wall of the nasal canal protrude into the posterior nares and have been described as the "nasal plugs". In their resting position the nasal plugs are pressed against the caudal wall of the nasal passage by the elasticity of the tissues. In this position they seal off the upper narial complex from the bony nasal canals. On their dorsal aspect there are distinct grooves into which a tendinous, and frequently cartilaginous, outgrowth of the caudal wall of the nasal canal fits. Thus, when the posterior parts of the nasofrontal sacs are inflated, downward pressure is exerted on the nasal plugs so that they are prevented from moving upwards. The nasal plugs can also be actively pulled in a rostral direction by a pair of nasal plug muscles, which consist of short red muscle fibres intercalated between tendinous strands of white fibrous tissue.

From their origin, partly on the premaxillary bones and partly on the melon, the amount of red muscle fibres diminishes towards the insertion of the muscle into the connective tissue of the plugs. The rostrad movement of the plugs is made possible by the presence of a pair of premaxillary air sacs. These sacs are rostral diverticula of the nasal canal and whilst their dorsal walls form the ventral lining of the nasal plug muscles, their ventral walls cover the smooth surfaces of the premaxillary bones.

Upon removing the blubber from the externally symmetrical head, it is disclosed that the arrangement of air sinuses and muscular systems are markedly asymmetrical. These structures are generally larger on the right hand side, and in some instances e.g. in Kogia, this asymmetry is so exaggerated that some structures are totally absent from the left. This asymmetry of the soft parts is reflected in the bones surrounding the nasopalatine canals, in so far as the muscles of the nasal passage originate on them, or as they are covered by the epithelium of the premaxillary sacs. Subsequently the functional diameter of the left nasopalatine canal is greater than that of the right. An extreme example of this asymmetry can be found in the Physeteridae. Reverse asymmetry in the formation of the skull has, as yet, not been found.

Lawrence \& Schevill (loc. cit.) concurred with the opinion of Huber (1934) that "all muscle layers rostral to the cranium and dorsal to the rostrum represent the singly developed $\mathrm{m}$. maxillonasolabialis". Huber (1934) stated that "the pars nasalis has become the part intrinsic to the blowhole region, while the pars labialis forms the musculature of the rostral part of the head, including the portion associated with the melon". As the appearance of both parts differs considerably I prefer to distinguish two separate muscles: the m.maxillonasalis and the m.maxillolabialis (fig. 4).

According to Lawrence \& Schevill (1956) the

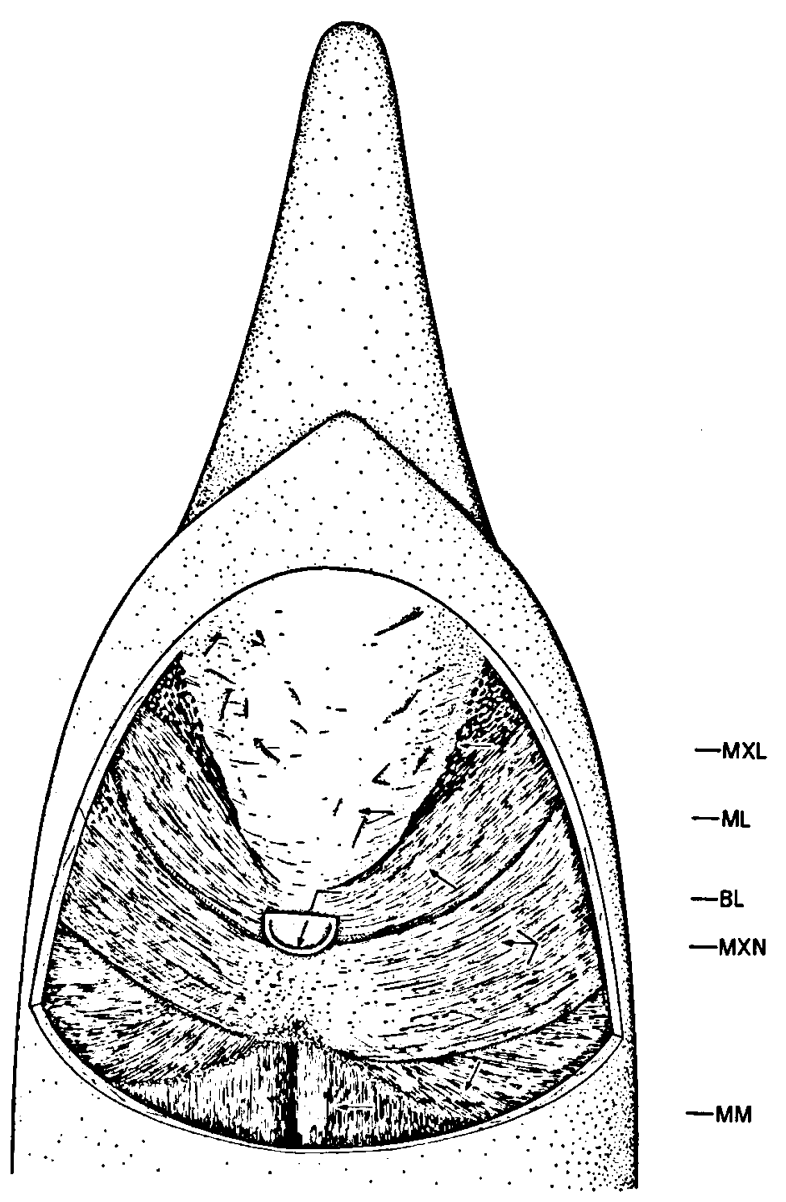

Fig. 4. Dissection of the superficial layers of the $\mathbf{m}$. maxillonasalis and $\mathrm{m}$. maxillolabialis in Stenella coeruleoalba. For abbreviations see page 157. 
maxillonasal muscle can be divided into six different layers that are, however, not always easy to distinguish. This division is made on the basis of the level of insertion of the muscle fibres. The layers having their insertion above or at the level of the vestibular air sacs form the "externus group", subdivided into an "anteroexternus", predominantly rostral to the nasal passage, a "posteroexternus", predominantly caudal to the nasal passage, and an "intermedius" situated between these two parts. The layers having their insertion deep to the externus group, but superficial to, or on the level of the nasofrontal air sacs, belong to the "internus group", subdivided into an "anterointernus" and a "posterointernus". All layers lying beneath this level belong to the "profundus" that is not subdivided. Lawrence \& Schevill (1956) also described major and minor "intrinsic muscles" that are functional on the caudal section of the nasofrontal air sacs. These are minute sheets of muscle originating at the supraoccipital crest and inserting into the rostral wall of these diverticula. In my opinion these are part of the "posterointernus".

In the different species examined by me there was considerable variation in these muscular lay. ers and in the orientation of the fibres within them. This was mainly the result of the degree of their development and the disposition of the air sacs and the nasal tract. The variation was also reflected in the degree of development of the maxillary and premaxillary bones. Considerable differences were found within the same species when young and old individuals were compared. In the young, the nasal passage was situated more rostrad in relation to the cranium, and so, in delphinids, the dorsal aspect of the skull in this region was rather convex. In older specimens, however, the maxillary and premaxillary bones were more caudally extended, and with age they covered eventually the frontal bone completely (fig. 2). This gave the dorsal aspect of the skull a concave appearance. It is clear that this development is related to changes in the origin of the posteroexternus and - internus with consequent changes in the orientation of the muscle fibres. The relationship of this change in orientation will be referred to in the discussion. In all animals possessing the full set of diverticula, all six layers can be recognized more or less easily. The morphology of the various layers depends on that of the development of both the diverticula and the skull in the nasal region.

\section{MATERIAL AND METHODS}

Most of the material used in the present study was preserved by deep-freezing. Exceptions were a foetus of Lagenorhynchus albirostris which was preserved in $70 \%$ alcohol, and the heads of Stenella frontalis, Physeter macrocephalus foetus, and Pontoporia blainvillei which were preserved in formalin.

All frozen specimens were dissected completely after partial thawing, during which measurements and weights were taken, together with notes concerning the state of preservation and possible diseases and infections of the animals and their organs. The skulls and skeletons are in the collections of the Institute of Taxonomic Zoology (Zoologisch Museum) of the University of Amsterdam and the Rijksmuseum van Natuurlijke Historie, Leiden.

The different layers of muscles connected with the blowhole region were dissected layer by layer, keeping adjacent structures intact as much as possible. The function of each layer of muscle was determined by stretching and relaxing the muscle in the direction of its insertion and origin. Since all odontocetes are markedly asymmetrical, this procedure had to be carried out on both sides.

During the initial stages of this study, air was pumped through the larynx before dissection in order to inflate the air sac system, for the determination of its function and to delineate the air sacs themselves. This technique was later abandoned, since, in the absence of integument, blubber and muscle tonus, a distorted picture of the size, shape, and volume of the air sacs was obtained. Also unsuccessful was polyester resin injection of the respiratory tract, which proved injurious to the epithelial lining required for histological examination, and caused enormous shrinkage of the casts. The best results were obtained by injection of silicone rubber latex since this substance contains a wetting agent allowing the fluid to enter the smallest cavities. This material hardens fairly rapidly, hence in the event of shrinkage more fluid can be added to obtain a complete filling.

During a study of the architecture of the skull, radiographs were taken of several species at various ages. This was to determine the changes which took place in the general morphology and texture of the bone. Serial microscopic slides of a foetal specimen of Phocoena phocoena were also examined.

The distribution of sound energy in the skull, 
emanating from an ultrasonic whistle placed in the posterior nares, was measured by a piezoelectric device mounted on a suture needle as described by Purves (1966).

The material for the present study consisted of the following specimens:

\section{PLATANISTIDAE \\ Pontoporia blainvillei \\ head, coll. Pilleri no. 469. \\ HYPEROODONTIDAE \\ Hyperoodon ampullatus \\ head, BMNH. \\ Mesoplodon bidens \\ \%, head, coll. Dolfinarium Harderwijk: \\ $\$$, neonatal, coll. Dolfinarium Harderwijk.}

\section{PHYSETERIDAE}

Kogia simus

head, Dr. P. B. Best, South Africa.

Kogia breviceps

head, ZMA 14.817; head, ZMA 15.241.

Physeter macrocephalus

head, $150 \mathrm{~cm}$ foetus, BMNH.

\section{PHOCOENIDAE}

Phocoena phocoena

\&, L. $160 \mathrm{~cm}$ (WO 31);

o, L. $140 \mathrm{~cm}$ (WO 63, ZMA 7559);

$\hat{\delta}$, L. $147 \mathrm{~cm}$ (WO 67, ZMA 7623);

ô, L. $110 \mathrm{~cm}$ (WO 72, ZMA 8651);

\&, L. $126 \mathrm{~cm}$ (WO 74);

$\hat{o}$, L. $116 \mathrm{~cm}$ (WO 75);

ô, L. $124 \mathrm{~cm}$ (WO 76);

ô, L. $132 \mathrm{~cm}$ (WO 87);

\&, L. $146.5 \mathrm{~cm}$ (WO 92, ZMA 11.650);

$\hat{\delta}$, L. $118 \mathrm{~cm}$ (WO 94, ZMA 12.983);

$\hat{\delta}$, L. $118 \mathrm{~cm}$ (WO 95, ZMA 13.138);

q, L. $153 \mathrm{~cm}$ (WO 98, ZMA 13.247);

\%, L. 154 cm (WO 99, ZMA 13.413);

ô, L. $136 \mathrm{~cm}$ (WO 100, ZMA 13.834);

\&, L. 124 cm (WO 101, ZMA 13.835);

§, L. $131 \mathrm{~cm}$ (WO 102, ZMA 13.836);

ô, L. $151 \mathrm{~cm}$ (WO 108, ZMA 14.336);

\&, L. 139 cm (WO 109, ZMA 14.337);

\$, L. $126.5 \mathrm{~cm}$ (WO 110, ZMA 14.292);

ô, L. $149 \mathrm{~cm}$ (WO 119, ZMA 14.517);

१, L. $158 \mathrm{~cm}$ (WO 123, RMNH 21738);

今, L. $136.5 \mathrm{~cm}$ (WO 128, RMNH 22214);

\&, L. $115 \mathrm{~cm}$ (WO 130, ZMA 15.095);

ㅇ, L. $155 \mathrm{~cm}$ (WO 133, ZMA 15.136);

$\hat{\delta}$, L. $89 \mathrm{~cm}$ (WO 141, ZMA 15.209);

ô, L. $134 \mathrm{~cm}$ (WO 144, ZMA 15.390);

\$, L. $155 \mathrm{~cm}$ (WO 145, ZMA 15.391);

\&, L. $112 \mathrm{~cm}$ (WO 153, ZMA 15.625);

\%, L. $116 \mathrm{~cm}$ (WO 155, ZMA 15.668).

\section{DELPHINIDAE}

Cephalorhynchus hectori

ô, L. $118 \mathrm{~cm}$ (WO 104, ZMA 14001).

Lissodelphis borealis

o, BMNH.
Orcinus orca

head, BMNH; $\delta$, coll. Dolfinarium Harderwijk.

Lagenorhynchus albirostris

\&, L. $223 \mathrm{~cm}$ (WO 77, ZMA 9478);

ô, L. $43 \mathrm{~cm}$ foetus (WO $43 \mathrm{f}$ );

o, L. 269 cm (WO 88, ZMA 10.746);

$\delta$, L. $250.5 \mathrm{~cm}$ (WO 89);

\&, L. $262.5 \mathrm{~cm}$ (WO 90, ZMA 11.384);

\%, L. $218 \mathrm{~cm}$ (WO 91, ZMA 11.517);

ㅇ, L. $255 \mathrm{~cm}$ (WO 97, ZMA 12.982);

\&, L. $264 \mathrm{~cm}$ (WO 140, ZMA 15.208);

$\hat{o}$, coll. Dolfinarium Harderwijk.

Lagenorhynchus acutus

q, L. $157 \mathrm{~cm}$ (WO 83, RMNH 19535).

Lagenorhynchus obliquidens

\&, L. $180.5 \mathrm{~cm}$ (WO 82, ZMA 10.237).

Lagenorhynchus obscurus

o, L. $165 \mathrm{~cm}$ (WO 113, ZMA 14.335A);

\&, L. $171.5 \mathrm{~cm}$ (WO 116, ZMA 14.359);

ô, L. $83 \mathrm{~cm}$ neonatus (WO 127, ZMA 14.764);

\&, L. $171 \mathrm{~cm}$ (WO 154, ZMA 14.818).

Tursiops truncatus

\%, L. $345 \mathrm{~cm}$ (WO 73, ZMA 8164);

\&, L. $326 \mathrm{~cm}$ (WO 86, ZMA 10.504);

\&, L. $162 \mathrm{~cm}$ (WO 136, ZMA 15.383);

\&, L. $233 \mathrm{~cm}$ (WO 137, ZMA 15.384);

\&, L. $222 \mathrm{~cm}$, coll. Dolfinarium Harderwijk.

Stenella coeruleoalba

ô, L. $156 \mathrm{~cm}$ (WO 85, RMNH 19621).

Stenella longirostris

, BMNH.

Stenella frontalis

head, ZMA 15.171.

Delphinus delphis

\&, L. $222 \mathrm{~cm}$ (WO 84, ZMA 10.503);

๙ิ, L. $183 \mathrm{~cm}$ (WO 93, ZMA 11.887);

$\hat{\delta}$, L. 217 cm (WO 103, ZMA 14.002);

\$, L. $206 \mathrm{~cm}$ (WO 106, ZMA 14.119);

\&, L. 137 cm (WO 107, ZMA 14.289);

ô, L. $176 \mathrm{~cm}$ (WO 120, ZMA 14.516);

ô, L. $207.5 \mathrm{~cm}$ (WO 122, ZMA 14.540);

$\delta$, L. $235 \mathrm{~cm}$ (WO 131, ZMA 15.140);

$\hat{\delta}$, L. 230 cm (WO 132, ZMA 15.139);

\&, L. 198 cm (WO 134, ZMA 15.165);

$\hat{\delta}$, L. $194 \mathrm{~cm}$ (WO 135, ZMA 15.166);

\&, L. 174 cm (WO 136, ZMA 15.168);

o, L. $199 \mathrm{~cm}$ (WO 137, ZMA 15.169);

\&, L. $106.5 \mathrm{~cm}$ (WO 138, ZMA 15.211);

๙ิ, L. $167 \mathrm{~cm}$ (WO 139, ZMA 15.212);

ઈ, L. 203 cm (WO 146, ZMA 15.396);

§, L. $193 \mathrm{~cm}$ (WO 147, ZMA 15.425);

ô, L. $188 \mathrm{~cm}$ (WO 148, ZMA 15.513);

\&, L. $142.5 \mathrm{~cm}$ (WO 151, ZMA 15.528).

\section{STENIDAE}

Sotalia guianensis

今, L. 265 cm (WO 81, ZMA 10.745);

\&, L. $182 \mathrm{~cm}$ (WO 112, RMNH 21755);

\&, L. $165 \mathrm{~cm}$ (WO 114, RMNH 21756);

o, L. 187 cm (WO 115, RMNH 22259);

o, L. $183.5 \mathrm{~cm}$ (WO 117, RMNH 22260);

ô, L. $157 \mathrm{~cm}$ (WO 118, RMNH 22258);

ô, L. $146 \mathrm{~cm}$ (WO 124, RMNH 22256);

A, L. $167 \mathrm{~cm}$ (WO 125, RMNH 22257); 
\%, L. $171 \mathrm{~cm}$ (WO 126, ZMA 14.641);

\&, L. 152 cm (WO 149, ZMA 15.515);

ô, L. $176 \mathrm{~cm}$ (WO 150, ZMA 15.527);

\&, L. $158.5 \mathrm{~cm}$ (WO 152, ZMA 15.571).

Abbreviations:

$$
\begin{aligned}
\text { WO = } & \text { Walvis Onderzoek, Zoological Laborato- } \\
& \text { ry, University of Amsterdam; } \\
\text { ZMA }= & \text { Zoological Museum, Amsterdam; } \\
\text { RMNH }= & \text { Rijksmuseum van Natuurlijke Historie, } \\
& \text { Leiden; } \\
\text { BMNH }= & \begin{array}{l}
\text { British Museum (Natural History), } \\
\text { London; }
\end{array} \\
\mathbf{L}= & \begin{array}{l}
\text { Total length (tip of snout to notch in } \\
\text { flukes). }
\end{array}
\end{aligned}
$$

\section{RESULTS}

\section{The anatomy of the nasal tract}

Family Platanistidae: Pontoporia blainvillei.

The anatomy of the nasal tract complex of Pontoporia has been dealt with at some length by Schenkkan (1972) but for purposes of comparison it is necessary to reiterate briefly a description of some of the main features in this family. Pontoporia is characterized by a hyperdevelopment of the right vestibular sac (fig. 13-1). A branch of this diverticulum crossed over the mesial axis of the head anterior to the blowhole to a point near the rostral margin of the left vestibular sac. Purves (pers. comm.) states that this condition also occurs in Inia, and Schenkkan \& Purves (1973) found a similar arrangement in Kogia. The posterior sections of the nasofrontal air sacs were small bulbous structures caudal to the blowhole, but rostral sections were absent. The premaxillary sacs were relatively small. The nasal plugs showed, on their dorsal free borders, small ventro-laterally directed grooves, fitting exactly into the slitlike orifices of the bulbous nasofrontal sacs. The blowhole musculature resembled that found in most other odontocetes. There were no accessory air sacs.

To demonstrate the extent of premaxillary sac importance throughout the suborder, the following index was designed. This expresses their maximum width as a percentage of the maxillary bones at this level. Within the Platanistidae this value amounts to $14 \%$ in Platanista, 30\% in Pontoporia, and $33 \%$ in Inia.
Family Hyperoodontidae: Mesoplodon bidens.

The skull of most species in this family shows a characteristic not present in other members of the Odontoceti, viz. a pronounced upward curvature of the posterior extremity of the maxillary bones (fig. 5). The premaxillary bones spreading laterally round the nares form extensive anteriorly directed surfaces, in front of the supraoccipital crest. This crest also shows a marked asymmetry. The general topography of the nasal region of the skull has been regarded as a diagnostic feature between the various species. It will be shown, however, that the peculiarities of the skull in this region are also due to the disposition of the various diverticula and the muscles of the nasal tract, but these are subject to considerable variability!

The blowhole was relatively large, its greatest width constituting $20 \%$ of the total width of the head as opposed to $10-16 \%$ in other odontocetes. It was displaced to the left, situated on top of the head. Immediately deep to the blowhole was found the vestibule, completely occluded by the lips of the blowhole. On the right side the rostral wall of the vestibule, forming its floor, showed a convexity which was extended as the ventral wall of the right vestibular air sac ("erste Klappe", Hanke, 1914). On the left side there was no such convexity. The vestibular sacs were small laterocaudal extensions of the vestibule (fig. 13- 17), the walls consisting of wrinkled, black pigmented epithelium. The dorsal walls were overlaid by tough tissue of tendinous fibres forming the insertions of the superficial layers of the posteroexternus of the maxillonasalis muscle. Mesially, the vestibular air sacs were bordered by the notch of the supraoccipital crest. Deep to the vestibular sacs the nasal tract continued ventrally towards the bony nares as a narrow tube, flattened antero-posteriorly. In the caudal wall, under a gabled membranous ligament, narrow slits gave entrance to the caudal sections of the nasofrontal air sacs. The anterior parts of these diverticula were small in comparison with the caudal sections lining the whole smooth area of the premaxillary bones, caudal to the nasal tract.

The nasal plugs ("zweite Klappe", Hanke, 1914), showed, on their dorsal free borders, the same small ventro-laterally directed grooves, as described for Pontoporia fitting exactly into the slitlike orifices to the nasofrontal diverticula. The 


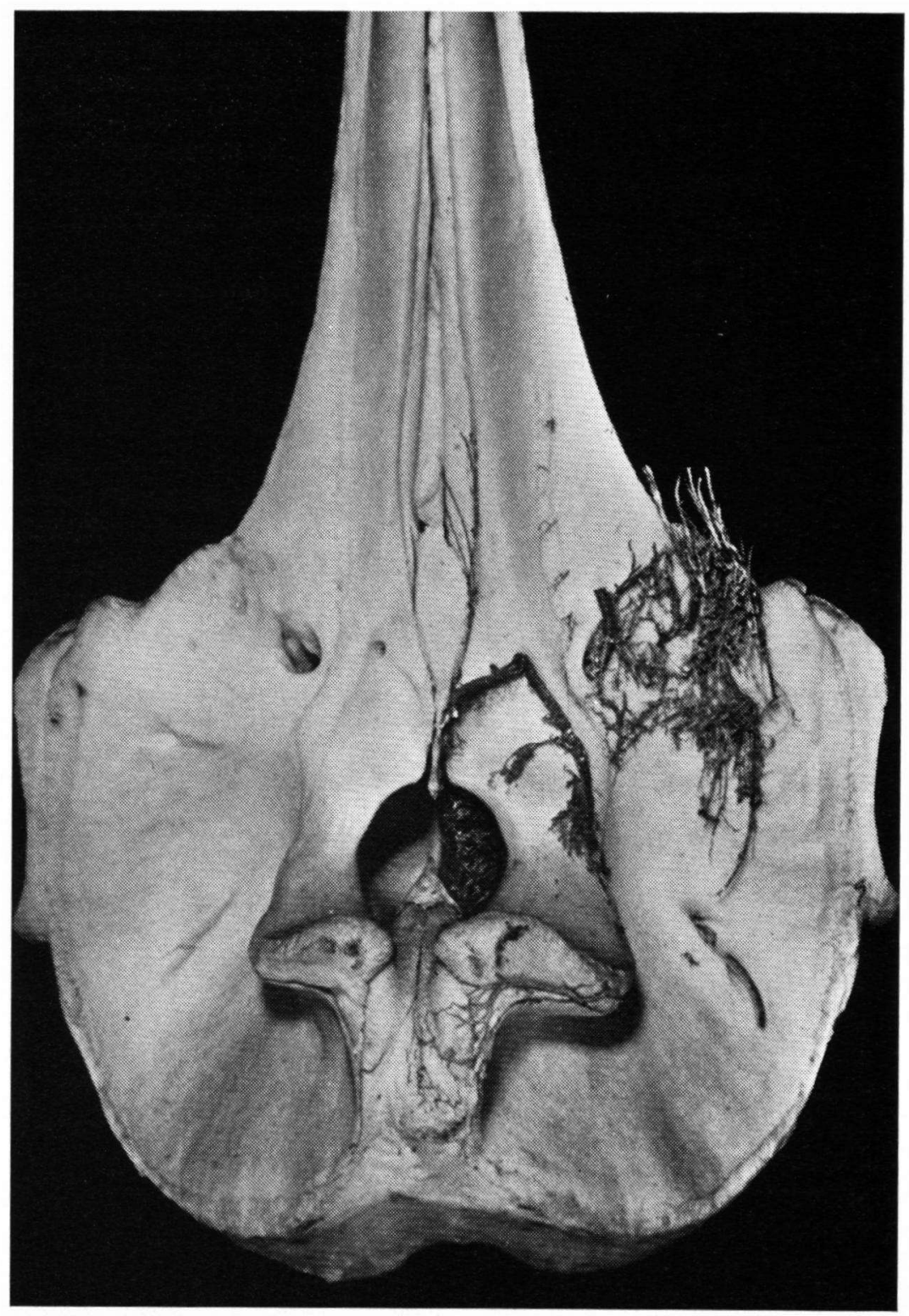

Fig. 5. Photograph of the dorsal aspect of the skull of Mesoplodon bidens showing the upcurved premaxillary bones and the plastic resin cast of the bulbous arterio-venous plexus in the right nasopalatine canal. Photograph British Museum (Natural History), by courtesy of Dr. P. E. Purves.

anterior part of the right nasofrontal sac was well developed in both specimens dissected by me. On the left side, however, it was only half the size of that of the right side. This arrangement is contrary to the situation found in an old male specimen dissected by Purves (pers. comm.). He found an enormously developed anterior section of the nasofrontal sac of the right side whilst that of the left side was absent.

In both my specimens no accessory air sacs were present. The entrances to the premaxillary diverticula were very narrow slits in the rostral wall of each nasal passage, leading into relatively small premaxillary sacs. The narrowness of these orifices was due to the fact that the posterior margin of the nasal plugs had a membranous attachment to the entire anterior border of the bony nares, contrary to the condition found in most odontocetes in which the plugs are attached only to the nasal septum. 


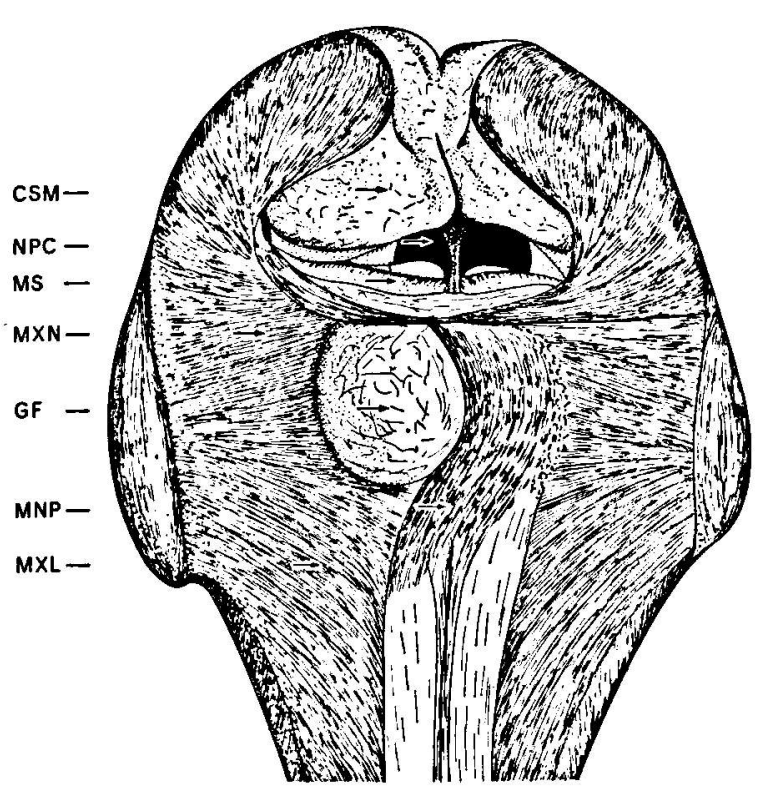

Fig. 6. Dissection of the nasal passage in Mesoplodon bidens demonstrating the globular mass of adipose tissue, rostral to the right naris and the curvature of the nasal plug muscles. After a sketch by Dr. P. E. Purves. For abbreviations see page 157 .

The nasal plugs in this group were elongated dorso-ventrally and not flattened dorso-ventrally as in most delphinids. They did not possess lateral valvular flaps as are present in the latter. 1 consider this situation to be of essential acoustic importance (see discussion). Superficial to the right premaxillary sac was a globular mass of adipose tissue which was clearly developed independently of the melon (fig. 6). The presence of this mass of adipose tissue had caused a distortion of the maxillolabialis and right nasal plug muscles. From their origin on the right premaxillary bone, these muscles swept round the left side of the aforementioned mass of adipose tissue to mingle with the fibres of the left nasal plug muscle. This displacement to the left, of the insertion of muscles which properly belong to the right side, has already been noted in respect of Kogia (Schenkkan \& Purves, 1973). The possible functional significance of the globular mass of fat will be discussed later.

The peculiar outgrowth of the premaxillary and maxillary bones forming an elevated supraoccipital crest was related with a change in direction of the fibres of the posterior part of the maxillonasal muscle. The more superficial layers ran horizontally in a caudo-rostral direction, whilst the deeper layers followed at first the concave surface of the maxillary bones, and swept round the lateral margin of the expanded premaxillae, running thereafter mesially in a tendinous fascia to be inserted into the posterior wall of the nasal passage. The other layers were comparable in form with those in the delphinids. The width of the premaxillary sacs constituted $36 \%$ of the total maxillary width.

\section{Family Hyperoodontidae: Hyperoodon ampullatus.}

The skull of this genus is broadly similar to that of Mesoplodon, showing the same elevation of the supraoccipital elements of the maxillary and premaxillary bones. The most characteristic feature, however, is formed by a pair of large maxillary crests, relatively shallow in the juvenile specimen examined (fig. 7). But in the old animal, especially in the male, they are extremely elevated and massive, their dorsal borders rising well above the supraoccipital crest, while the

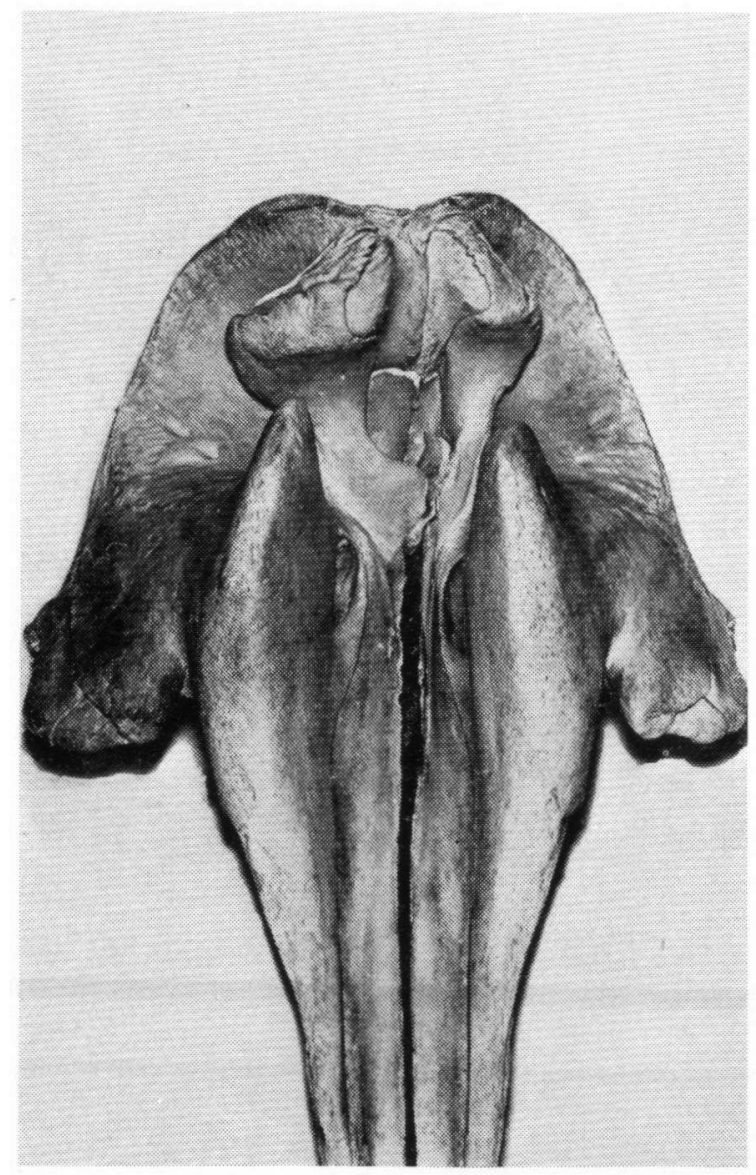

Fig. 7. Photograph of the skull of a young Hyperoodon ampullatus demonstrating the maxillary crests. Photograph Zoological Museum, Amsterdam, by courtesy of Dr. P. J. H. van Bree. 


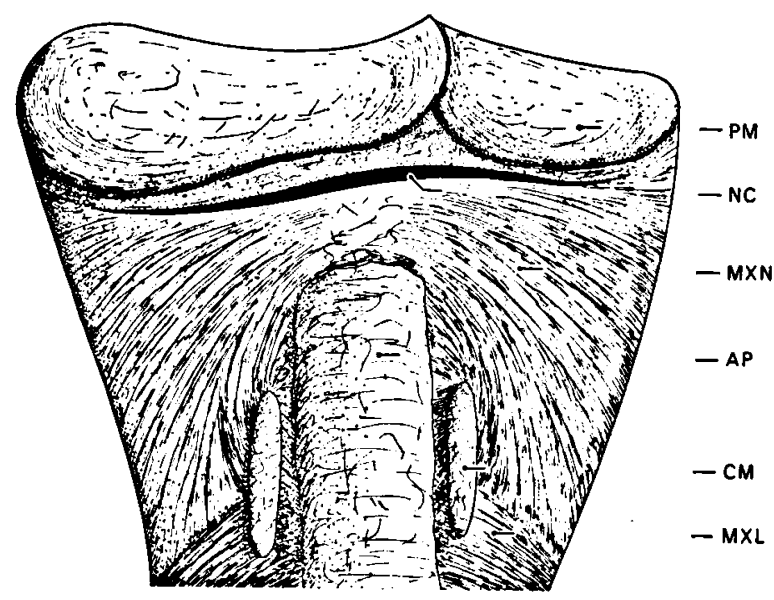

Fig. 8. Dissection of the nasal passage in Hyperoodon ampullatus showing the orientation of the $\mathrm{m}$. maxillonasalis and $\mathrm{m}$. maxillolabialis and the adipose pad between the maxillary crests. For abbreviations see page 157.

mesial aspects of this region are closely opposed to each other. Norris (1964) assigned an acoustic function to these maxillary crests, a view with which I do not agree. The possible functional significance of these crests is referred to in the discussion. This elevation of the maxillary bones was correlated with a profound modification in the position of the insertion and the direction of traction of the $\mathrm{mm}$. maxillonasalis and maxillolabialis (fig. 8). Thus the superficial layers of the maxillonasalis originated on the posterior $2 / 3$ of the lateral aspects of the maxillary crests and swept dorso-caudally to become inserted on the rostral wall of the nasal passage. The maxillolabial layers originated both on the lateral and mesial aspects of the anterior part of the maxillary crests and were inserted anteriorly into a mass of adipose tissue, commonly referred to as the melon, and posteriorly into a thick pad of fibrous tissue covering the dorsal surfaces and interval between the maxillary crests. It was evident that during development the maxillary crests had occupied a space between the superficial and deep layers of the maxillolabial muscle. In common with the condition in Mesoplodon, the posterior parts of the maxillonasalis followed the deep, concave surface of the maxillary bone, curving laterally round the expanded premaxillary bones and inserted tendinously into the caudal wall of the nasal passage. The blowhole was markedly displaced to the left and consisted of a shallow, crescent-shaped slit, measuring $10 \mathrm{~cm}$ across the

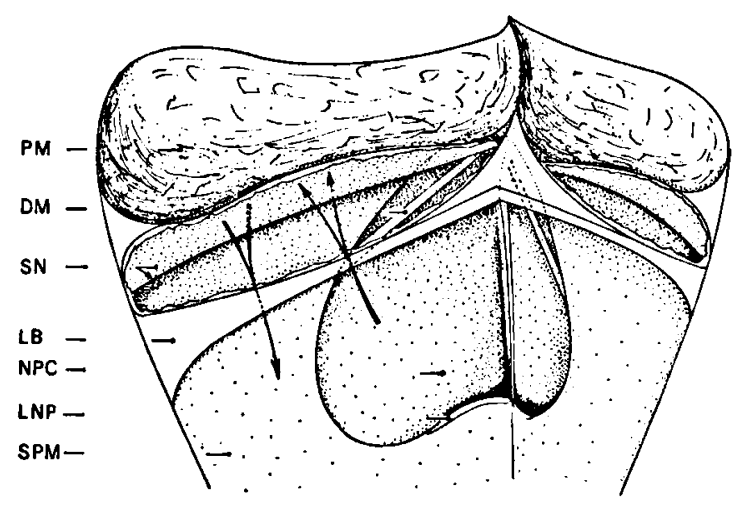

Fig. 9. Dissection of the nasal passage in Hyperoodon ampullatus demonstrating the caudal sections of the nasofrontal sacs after removing the rostral walls. The arrows indicate the possible flow of air. For abbreviations see page 157.

chord and constituting $20 \%$ of the total width of the head at this point. The blowhole led immediately into a wide vestibule, compressed caudorostrally, and measuring $21 \mathrm{~cm}$ at its widest point. There were no distinctly formed vestibular sacs but the epithelial lining of the lateral walls of the vestibule was very thin and membranous, suggesting that vestibular sacs would have been present in an ancestral form. This matter will be referred to in the discussion. Deep to the vestibule were found the lips of the upper nasal passage. The width of the right nasal passage was approximately twice that of the left one and the lips presented a curious scalloped appearance similar to that described as "museau de singe" in Kogia. This characteristic constitutes conclusive evidence that the "museau de singe" in the Physeteridae in fact is the entrance to the right nasal passage (Schenkkan \& Purves, 1973).

As in Mesoplodon the posterior part of the nasofrontal sac occupied the entire expanded anterior aspects of the premaxillary bones, curved in upward direction. Their slitlike orifices on the caudal wall of the nasal passages were guarded by stout, tendinous ligaments originating at the supraoccipital notch, and after passing diagonally across the nares, terminating at the suture between the maxillary and premaxillary bones.

The nasofrontal sacs were covered anteriorly by a membranous wall, which, upon removal, revealed a second membranous wall (fig. 9), protruding ventrally from the upper extremities of these 
sacs, thus partially dividing them into anterior and posterior compartments. The lower lateral extremities of the sacs continued into the general nasal passage and thence through a pair of narrow apertures into the premaxillary sacs like those in Mesoplodon. There were no anterior components of the nasofrontal sacs and no accessory sacs, Hyperoodon in this respect resembling the Platanistidae. The nasal plugs were greatly elongated dorso-ventrally, the right one being twice as large as the left. They had on their dorsal and lateral borders shallow grooves which fitted into the lower orifices of the nasofrontal sacs and were occupied by the tendinous ligaments mentioned above. The nasal plugs were attached to the mesial parts of the anterior margin of the nares but not as extensively as in Mesoplodon.

In the upper part of the bony nares was a conspicuous swelling of the posterior epithelial lining which was found to be composed entirely of an arterio-venous plexus with many arterio-venous anastomoses, and constituting quite clearly erectile tissue. Such a swelling was also found in the nares of Mesoplodon, Kogia, and only on the right side in Physeter. Figure 5 shows the narial region of a skull of Mesoplodon bidens in which the arterial system of the right side has been injected with a polyester resin. It will be seen that the cast of the capillary network of the bulbous swelling nearly occludes the right naris. The width of the premaxillary sacs constituted $30 \%$ of the total maxillary width.

\section{Family Monodontidae: Monodon monoceros.}

As I had no opportunity to examine original material of Monodon, I can only repeat briefly what has been stated about this species in the literature.

Huber (1934) described a capacious vestibule ("spiracular cavity"), situated somewhat caudoventrally to the blowhole and connected with two small lateral extensions or "lateral sacs" which are the homologues of the vestibular sacs of other odontocetes. He also described a pair of "nasofrontal sacs", as caudo-dorsal extensions of the nasal passage, ventral to the vestibule. From his figure one can conclude that these caudal diverticula each are divided into two components by a septum protruding from the mesial wall in a manner comparable with the situation found in Phocoena phocoena. The rostral extensions of these nasofrontal sacs, described by him as "antero-lateral sacs", are apparently homologous with the anterior parts of the nasofrontal sacs of other odontocetes. As he did not mention any accessory sac, it must be assumed that these are absent in Monodon. A pair of premaxillary sacs he described as lining the premaxillary bones, ventral to a pair of "valve plugs" or nasal plugs.

From Huber's very clear diagrams I get the impression that all the layers of the maxillonasal muscle slope in a dorso- rostral direction, in accordance with the relatively more anteriorly situated blowhole and nasal tract in this species. Huber described several discrete layers of the maxillolabialis, the fibres of which are also orientated rostro-dorsally and merge into the melon.

Examination of the premaxillary bones in the region of the premaxillary air sac showed that they have a strong convexity similar to that found in Pontoporia and constitute $28 \%$ of the maxillary width.

Family Delphinidae: Cephalorhynchus hectori.

The dorsal aspect of the skull of this species resembled that of Phocoena, showing the same slight asymmetry in comparison with the skulls of other odontocetes. However, whereas in older individuals of Phocoena there is a concavity, due to the dorsal ascent of the caudal extremity of the maxillary bones, in Cephalorhynchus the dorsal aspect of the skull in the nasal region is flat. Rostrad to the bony nares the premaxillary bones showed slight bulbous convexities, but less accentuated than in Phocoena; laterally they had a raised edge. As I only dissected one specimen of this species, the results must be interpreted with some reserve, since there might be great variation due to age and perhaps to sex, as observed in other species.

The vestibular sacs were situated somewhat laterally but mainly caudally to the nasal passage, they were small in relation to the size of the head. The caudal parts of the nasofrontal sacs were tubular and well developed. Just in between the two mesial terminations of these caudal sections, I found a small bulbous, translucent structure (diameter about $3 / 4 \mathrm{~cm}$ ) consisting of a tough, unstructurated gelatinous substance. In its position it was reminiscent of the hypothetical origin of the spermaceti organ in Physeteridae (Schenkkan \& Purves, 1973). The rostral sections of the na- 
sofrontal diverticula were greatly expanded, but flattened dorso-ventrally. With respect to the relative development of these rostral parts, there existed the extraordinary situation that the diverticulum of the left side was much larger than that of the right side, and crossed the midline to the right side of the head. Reverse asymmetry of the nasofrontal diverticula has not been found in any other species.

The accessory sacs were well developed and showed the normal asymmetry, the right diverticulum being about twice the size of the left one. Since the position of the nasal passage and the architecture of the skull resembled that of $\boldsymbol{P}$. phocoena, it was evident that the whole muscular arrangement of the nasal region was highly comparable with the situation described for the latter species. The premaxillary sacs were relatively quite small, constituting some $34 \%$ of the total maxillary width.

Family Delphinidae: Lissodelphis borealis.

The skull of this species was slender, the caudal extremities of the maxillary bones posterior to the bony nares were short in comparison to other species. This was due to the fact that these bones were rather flat and the occipital bones were well developed. The premaxillary bone of the right side was nearly twice as broad as the left in the nasal region. The bony nares were small.

In this species the melon was relatively large, so the nasal passage was displaced caudally. The vestibular sacs were situated caudally to the blowhole and large in relation to the size of the head. The rostral parts of the nasofrontal sacs were well developed and tubular. The lateral and caudal sections were tubular also and well developed, the lateral parts having the smallest diameter. In the lateral wall of this latter sections there were small bladderlike appendices. The accessory sac of the right side was very large and it even possessed an extension caudal to the orifice to the nasal passage. The accessory sac of the left side had a volume of about 1/9th of that of the right side. The premaxillary sacs were well developed, constituting $36 \%$ of the total maxillary width. The epithelium lining all diverticula was very thin but tough. Due to the caudad displacement of the nasal passage, the direction of all muscle fibres was nearly vertical and separation into various layers was therefore fairly difficult.
Family Phocoenidae: Phocoena phocoena.

As the upper part of the nasal tract in the Phocoenidae is strikingly aberrant compared to that in other odontocetes, it is necessary to describe some of the anatomical features at somewhat greater length than that apportioned to other species.

In Phocoena the vestibular sacs were more or less triangular in shape, the bases of the triangles being orientated caudo-laterally and their apices rostro-mesially (fig. 13-3). The rostral extremities of the right and left diverticula approached each other in front of the blowhole.

When the membranous dorsal walls of the vestibular sacs were removed, the ventral walls presented a disclike appearance, characteristic for this family. They were relatively thick and thrown into numerous transverse folds lying in near-semicircles round the slitlike entrance to the vestibule, which lay at right angles to the sagittal plane of the head. At the mesial and lateral ends of these orifices the ridges forming the floors of the sacs, met each other, those adjacent to the orifices being approximately straight, those furthest away almost semicircular. A sagittal section through the ventral wall of the vestibular sac shows that it is formed by a thick mass of complexly folded connective tissue, lined by a heavily pigmented epidermis (fig. 10). Thin strands of muscle fibres, from that layer of the maxillonasal muscle, which inserted into the floor of the vestibular sacs, passed upwards into the center of each ridge, the dorsal aspect of which was marked by a row of five small pits. The ridges bordering the slit were completely overlaid by the next pair of ridges. The whole assembly of ridges forms a dome-shaped mass which is strongly resistant to distortion by pressure from above, the slitlike orifice to the naris thereby remaining firmly occluded. If, however, pressure is exerted on their ventral aspect, the furrows separate and the orifice opens. From this arrangement it can be concluded that the more the vestibular sacs are inflated, the firmer will be the occlusion of the nares. This complex form of the vestibular diverticula is also found in Neomeris phocoenoides and Phocoenoides dalli.

The anterior parts of the nasofrontal sacs were well distended while the lateral parts were tubular. Both parts were embedded in loose connective tissue and lined by a thin, elastic epithelium, unpigmented in the majority of the speci- 


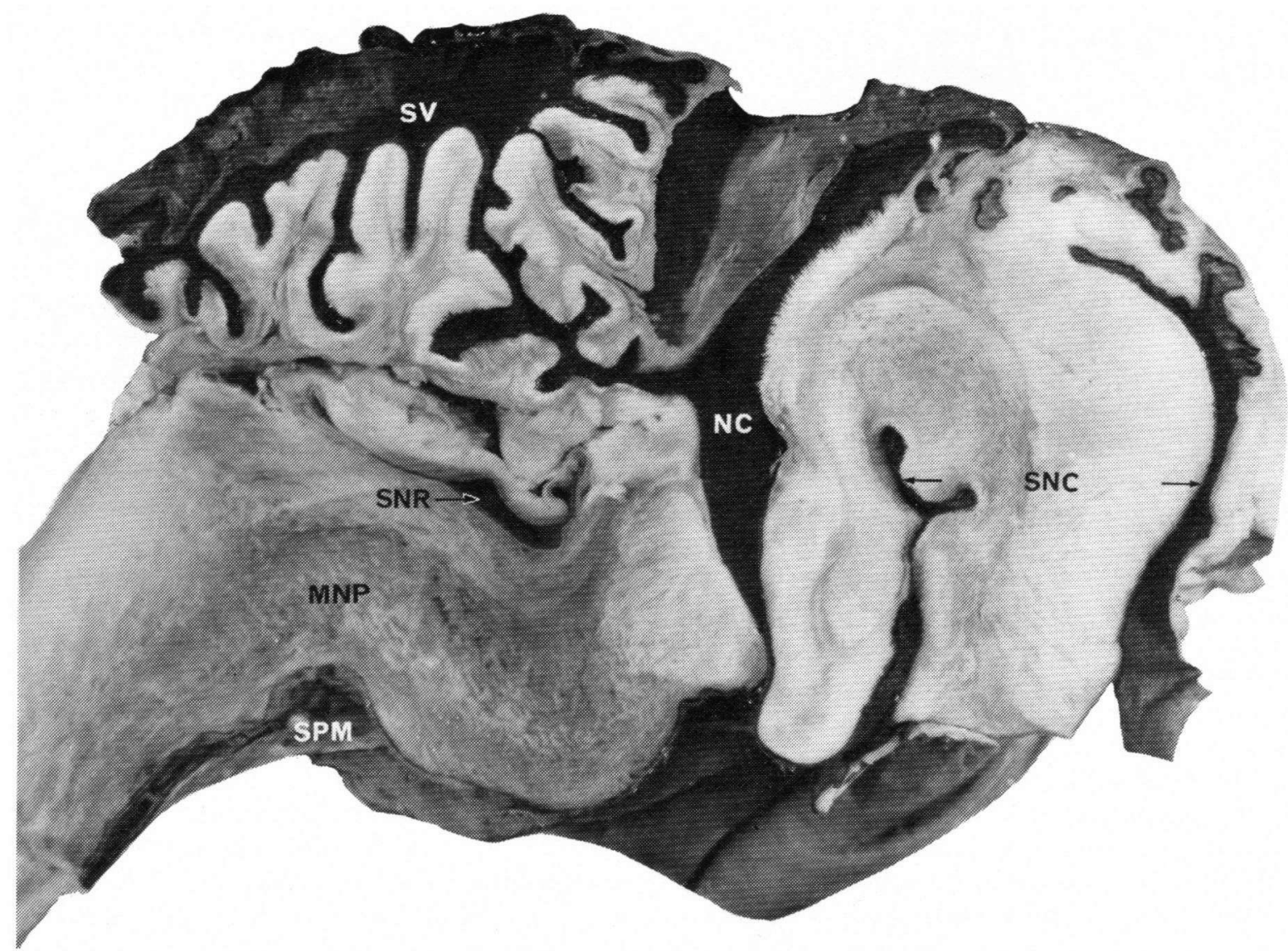

Fig. 10. Sagittal section through the nasal tract in Phocoena phocoena showing the complexly folded bottom of the vestibular sac. For abbreviations see page 157. Photograph S. van Mechelen.

mens examined. The caudal parts were divided into two contiguous cavities lying one behind the other, the partition consisting of a transverse outgrowth of the dorsal wall, directed ventrally. This septum consisted of connective tissue, interspersed between elements of cartilage, and lay at right angles to the nasal septum. Gruhl (1911) in referring to this structure, named the septa "Ethmoturbinale" and "hintere Klappe", respectively. It will be recalled that a similar condition of the caudal segment of the nasofrontal sac was found in Hyperoodon and Monodon. The orifice to both caudal and rostral components of the nasofrontal sac was slitlike and blocked by the transversely elongated, lateral margins of the nasal plugs. A tough, thin, tendinous membrane, stretching from the supraoccipital notch to the margin between the premaxillary and maxillary bones, was found on the caudal wall of the nasal passage, just beneath the orifice to the caudal section of the nasofrontal sac. This structure fitted into a groove on the dorsal aspect of the nasal plugs, and prevented them from displacing dorsally. This was the homologue of the "blowhole ligament" of Lawrence \& Schevill (1956).

In some specimens of Phocoena no accessory sacs could be traced (Schenkkan, 1971), whilst in others there were minute appendices of the lateral tubular sections of the nasofrontal sacs. In one or two specimens I found a real diverticulum, connecting with the nasal canal via the slitlike orifice into the caudal section of the nasofrontal diverticulum. In these cases, the nasal plugs showed an extra lateral extension protruding into this opening. In the present species, the premaxillary diverticula were relatively small and symmetrical. Their dorsal walls lined the ventral aspects of the nasal plug muscles as in other odontocetes. In this area the premaxillary bones showed a bulbous convexity as found in Pontoporia, Inia, and Monodon. They constituted $30 \%$ of the maxillary width in Phocoena. 


\section{Family Delphinidae: Orcinus orca.}

This species had a short and broad rostrum while in the nasal region, the skull was relatively symmetrical. The vestibular sacs were situated laterally to the blowhole. The nasofrontal sacs were tubular over their whole length and their terminations did not reach the mesial axis of the head. The caudal sections had a larger diameter than the rostral and lateral parts. The accessory sacs were relatively large and less pigmented than the other diverticula of the nasal passage. The premaxillary sacs were well developed, constituting about $47 \%$ of the total maxillary width. In relation to the cranium, the nasal passage sloped in rostrodorsal direction. The muscular arrangement was comparable with that in $\boldsymbol{P}$. phocoena.

Family Delphinidae: Lagenorhynchus albirostris.

The vestibular diverticula were very large and situated caudal and lateral to the nasal passage. The ventral walls of these diverticula were thicker than the dorsal walls, though not as thick as in Phocoena.

The nasofrontal sacs consisted of tubular caudal portions sloping dorsally along the nasal bones, their walls possessing small appendices. The rostral sections consisted of large bladderlike extensions occupying the whole area between the nasal passage and the melon. Small appendices were found in the dorsal walls of these extensions.

The accessory sacs were very large and both possessed a caudal part posterior to the orifice to the nasal passage. The rostral part of the accessory diverticula lay over a tough fibrous tendon, stretching from the caudal wall of the nasal passage near the nasal bones to the border between the premaxillary and maxillary bones.

In comparison with Phocoena the layers of the $\mathrm{m}$. maxillonasalis were orientated more steeply dorso-ventrally. Due to the enormously developed rostral extensions of the nasofrontal diverticula the anterior layers of this muscle were also more steeply orientated. Although the head of this species is larger than that of Phocoena, the muscular system is less developed. In the foetus of this species, the vestibular sacs were no more than small lateral extensions of the vestibule. The caudal part of each nasofrontal sac was already developed while the rostral part was no more than a tough tendon without a lumen. The accessory sacs were absent but the premaxillary sacs were well developed. The width of the premaxillary sacs in the adult constituted $40 \%$ of the total maxillary width.

\section{Family Delphinidae: Lagenorhynchus acutus.}

In this species the vestibular sacs were rather large and complex. They were placed caudal to the blowhole. A number of large lobes were found in the lateral edge of the sacs. In the lining of the walls of these diverticula collagenous fibres were found running in the direction of the long axis.

The nasofrontal diverticula were well developed, tubular structures. The caudal parts and the rostral terminations sloped dorsally. Mainly due to the caudal orientation of these diverticula, the nasal passages sloped in rostro-dorsal direction. Here also collagenous fibres ran in the direction of the long axis of the air sacs.

The accessory sacs were well developed, the right one having a section caudal to the orifice to the nasal passage, and occupying a groove formed by the raised border between the premaxillary and maxillary bones.

The premaxillary sacs were also quite large and occupied the whole broad part of the premaxillary bones rostral to the bony nares. Since the nasal passage ran somewhat obliquely rostro-dorsally, the muscular arrangement was such that most of the layers also ran about rostro-dorsad. All the layers could easily be distinguished. The layers placed caudally ran rostrad while the anterior layers were orientated steeply dorso-caudad. The premaxillary sacs constituted $43 \%$ of the total maxillary width.

\section{Family Delphinidae: Lagenorhynchus obliquidens.}

Since the right side in the single specimen examined was rather damaged due to an atrophy of all muscle layers and of a part of the diverticula, the left side only could be used for dissection. However, it must be remembered that this side is normally less developed than the right one. The left vestibular sac was capacious and situated mainly lateral to the nasal passage with the largest part rostral to the nasal canal. The caudal section of the nasofrontal sac was rather small and tubular in shape. The rostral part had a bladderlike rostral extension and was thinly walled and slightly pigmented. The asymmetry is best demonstrated by the state of development 
of the accessory sacs, but the fact that only the left side was available for dissection, made comparison with the right side impossible. The diverticulum on the left side was well developed.

The premaxillary sacs were large and well developed constituting $45 \%$ of the total maxillary width.

\section{Family Delphinidae: Lagenorhynchus obscurus.}

In this species there was a reverse asymmetry in the development of the vestibular diverticula, the left one being larger than the right one. They are rather well developed and caudal to the nasal passage.

The nasofrontal sacs were tubular over their whole length. Also in this species as well the rostral and caudal terminations sloped in a dorsal direction as described in L. acutus.

The accessory diverticula were well developed as were also the premaxillary sacs. The whole arrangement resembled the situation found in $\boldsymbol{L}$. acutus with the exception that the vestibular sacs were smaller in $L$. obscurus and showed the unusual reverse asymmetry mentioned above. The width of the premaxillary sacs constituted $51 \%$ of the total maxillary width.

\section{Family Delphinidae: Tursiops truncatus.}

This species is the one which has been studied most frequently in the past. The anatomical work of Lawrence \& Schevill (1956), based mainly on this species, is very clear and detailed. My results conform closely to their description, and small differences observed seem to result from a different state of development of the various structures due to age. In one specimen dissected I found that the left vestibular sac was larger than that of the right side (see also Lagenorhynchus obscurus). In the other specimens, the asymmetry was "normal". The left diverticulum reached more rostrad than the right. Also in all specimens the asymmetry of the nasofrontal diverticula conforms to that found normally throughout the suborder. They were tubular over their whole length and situated in a nearly horizontal plane. Near the entrance from the nasal passage I found a small ventral extension not present in other species. In one specimen the accessory sacs showed an excessive asymmetry, the right one being very large and the left one being merely a small extension of the nasofrontal sac. In the other spec- imens the degree of asymmetry was less. The right accessory sac was situated completely caudal to the tough tendon described previously in $L$. albirostris.

The premaxillary sacs were very large, constituting $45 \%$ of the total maxillary width and nearly consisting of two separate parts lying one above the other. Their ventral walls did not cover the broad part of the premaxillary bones completely. The direction of the muscle layers intrinsic to the nasal passage closely resembled that in L. albirostris, with the exception of the rostral layer which was orientated steeply, due to the fact that the diameter of the rostral section of the nasofrontal sacs was very small in $T$. truncatus compared with that in $L$. albirostris.

\section{Family Delphinidae: Delphinus delphis.}

The relatively small vestibular sacs were situated laterally to the nasal passage. The nasofrontal sacs were tubular over their whole length, the caudal section having a larger diameter than the rostral part. The caudal and rostral terminations turned dorso-mesially as described for $L$. acutus, the accessory sacs were not extremely large, though well developed. The premaxillary diverticula were large and broad and occupied $43 \%$ of the total maxillary width. The muscle layers intrinsic to the nasal passage were steep since the vestibular sacs were placed laterally and the nasal passage itself was nearly perpendicular to the rostrum.

\section{Family Delphinidae: Stenella.}

The species in this genus resembled each other very closely. In all three species, the relatively small vestibular diverticula were placed caudolaterally to the nasal passage. The nasofrontal sacs were tubular over their whole length, with the largest diameter in their lateral portion. The rostral and caudal terminations sloped in a dorso-mesial direction as described for $L$. acutus. The accessory sacs were relatively large and had a greater diameter than the nasofrontal sacs. Also in this genus the tough tendon was well developed. The premaxillary sacs were very large and broad, constituting $45 \%$ of the total maxillary width. The nasal passage itself sloped in a dorso-rostral direction, due to a displacement of the vestibular sacs in a caudal direction reflected in the otientation of the muscle fibres, intrinsic to the nasal passage as was observed in $L$. acutus. 
Family Stenidae: Sotalia guianensis.

Of this species I was able to dissect twelve specimens, young as well as old individuals. The variation, however, in the state of development was not very large. In most specimens the relatively large vestibular sacs were situated mainly lateral to the nasal passage. The nasofrontal sacs were tubular over their whole length, the caudal parts being the greater in diameter. The accessory sacs were well developed, but they were not very large. The premaxillary sacs were relatively small, occupying $42 \%$ of the total maxillary width. The muscular arrangement was comparable with the situation found in Delphinus delphis.

\section{Family Stenidae: Steno bredanensis}

(After Purves, 1966).

The relatively large vestibular diverticula were orientated laterally and sligthly caudally. The nasofrontal sacs were tubular throughout with a well developed accessory sac on the right side but a small one on the left. The premaxillary sacs were relatively small, occupying $43 \%$ of the total maxillary width.

\section{The rostrum}

The rostrum is composed of a number of elongated bones, the largest, forming its lateral parts, being the maxillae. Mesially to these are the premaxillary bones, which in turn are situated laterally to the mesial groove. This groove is filled by the mesethmoid, the anterior part of which is cartilaginous. The mesethmoid protrudes from the dorsal aspect of the navicular vomer. The ventral aspect of the rostrum is formed mainly by the maxillary bones bearing the homodont teeth. On the ventral aspect of the rostrum, posterior to the maxillary bones, are the palatine and pterygoid bones and a small part of the vomer visible between the maxillae. Small sections of the premaxillary bones can be seen anterior to the superficial part of the vomer.

In young animals the maxillae are composed of spongy bone but in older individuals a cross section of the rostrum shows very dense areas, in which the canaliculae of the bone are very small. In such cross sections it can be seen that the premaxillary bones consist mainly of spongy bone save for the dorsal parts which are composed of layers of very dense bone. In foetal and neonatal animals these are the only dense structures in the rostrum. The vomer is likewise composed of spongy bone. During the growth of the skull conspicuous changes occur in the region of the bony nares, especially during the development of the maxillae. In the neonatal skull, which is fairly symmetrical, in the dorsal aspect the maxillary, premaxillary, frontal, parietal and occipital bones are easy to distinguish and clearly visible, whilst the braincase is almost spherical. In the fullgrown animal, however, the caudal winglike posterior parts of the maxillary bones overgrow the frontal bone and together with the rostral part of the supraoccipital bone they turn dorso-rostrad, rendering the dorsal aspect of the skull concave. $\mathrm{X}$ ray photographs of rostra of $\boldsymbol{P}$. phocoena of different ages show differential bone densities. In a dorso-ventral radiograph of the rostrum of a neonatal specimen the premaxillary bones have a single very dense strand of bone, reaching from the bony nares up to the tip of the snout (fig. 11,A). Within this strand, however, the fibres are of heterogeneous density. No density differentiation can be traced in the maxillary bones. Older specimens, viewed in the same plane, also exhibit similar dense strands in the premaxillary bones, but in addition a strand of dense material can be observed in the maxillae, in a position lateral to the premaxillae. These strands are of similar width and are orientated virtually parallel to those in the premaxillae. Near the tip of the snout the strands in the maxillae diverge towards the lateral margin of the rostrum. In the rostrum of a very old animal three or more dense strips are visible. These are positioned laterally to the strand in the maxillae mentioned above, and all diverge towards the lateral margin (fig. 11,B).

Correlating these observations with those from sound transmission experiments carried out on macerated skulls in the manner described by Purves (1966), it becomes evident that secondary and tertiary maxima of intensity are found at the places where the dense areas in the maxillary bones reach the lateral margin of the rostrum. It is conceivable that, since the animal is producing sound emissions of high intensity all its life, the regions of maximum energy could induce the formation of dense strands in the rostrum.

In the same radiograph the shadow of the arrowpoint-shaped vomer was visible between the premaxillae. Comparing a series of dorso-ventral $\mathrm{X}$-ray projections of $\boldsymbol{D}$. delphis of different ages, 

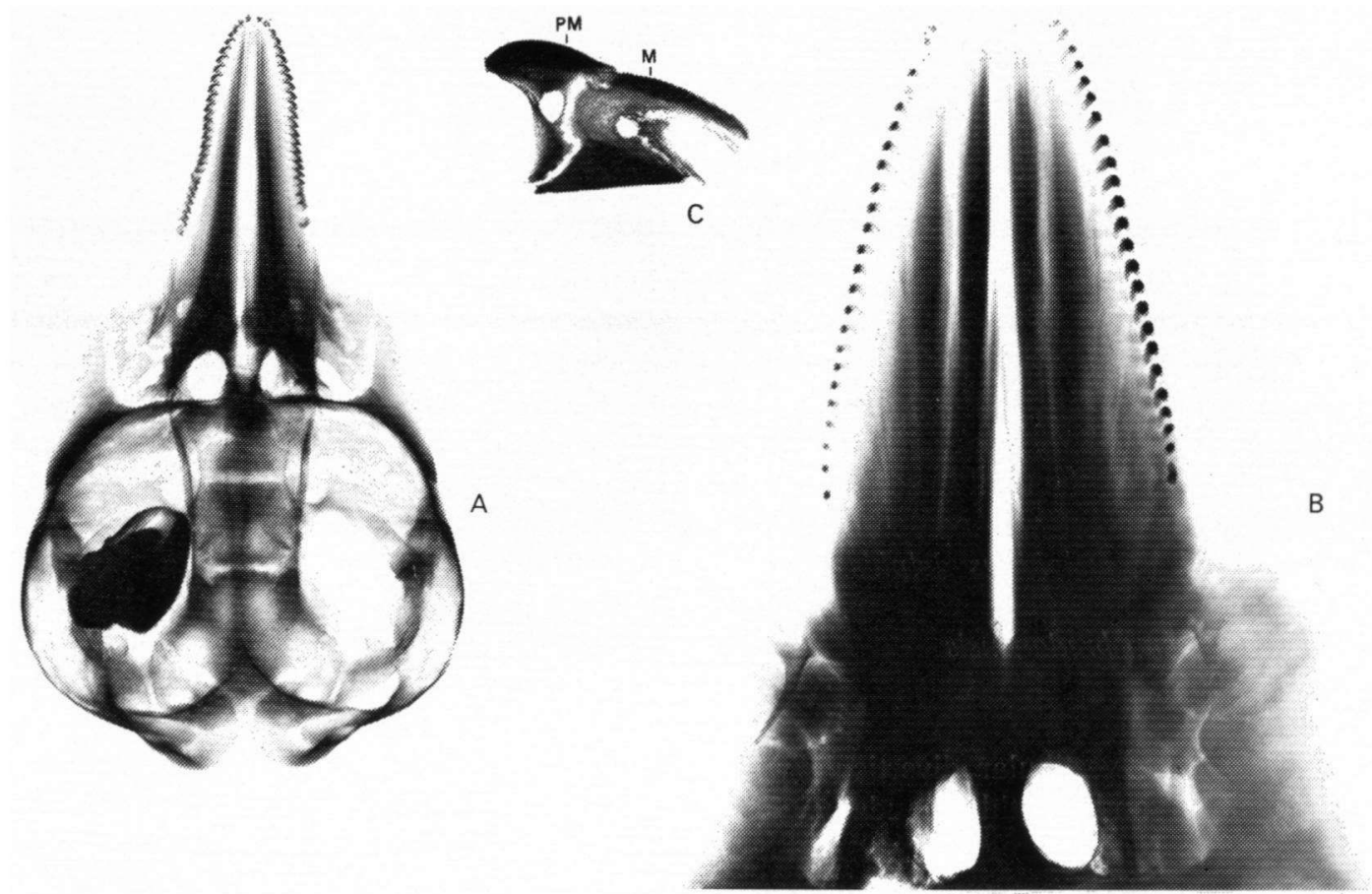

Fig. 11. Radiographs demonstrating the presence of dense strands in the maxillae and premaxillae in A. dorsoventral projection of the skull of a neonatal Phocoena phocoena, B. same projection of the rostrum of an old Phocoena phocoena, C. rostro-caudal projection through a slice of the right side of the rostrum of an old Tursiops truncatus.

the same tendency towards differentiation of the bone can be found. In the premaxillary bone of a 16 weeks old animal I found a strand of very dense bone that terminated near the tip of the snout in two diverging filaments, but in the maxillary bones dense strands were absent.

In the rostrum of a juvenile specimen there were in addition to the strands in the premaxillary bones, in each maxillary bone four strands of denser material terminating in succession on the lateral edge of these bones. In the rostrum of an older individual more of these strands could be seen, the material being most dense mesially. In this species the divergence of the strands was less obvious than in $\boldsymbol{P}$. phocoena. This was to be expected since the rostrum is narrower. In a juvenile specimen of Cephalorhynchus hectori the dense areas in the premaxillary bones were present as in $D$. delphis and $P$. phocoena, but in the maxillary bones only very thin strands were discernable. The rostrum of Sotalia guianensis, Tursiops truncatus and other species, including Kogia breviceps, all showed the same features, the densest structure being found in the premaxil- lary bones, reaching from the bony nares to the tip of the snout. In the maxillary bones various areas of dense bone terminated at the lateral margin of the maxillary bones. In $\boldsymbol{P}$. phocoena the "secondary" dense strands in the maxillary bones diverged conspicuously and were denser than in the other species. These data suggest that the rostrum may transmit vibrations longitudinally along the dense strands which are separated by strands of more cancellated bone. The strands terminating in a line on the lateral edge of the rostrum, together with those ending at its tip, may possibly form sites of emission.

To investigate whether the difference in the rostrum between Phocoena phocoena and the other species is of functional significance, a second series of experiments was carried out. The experimental procedure for sound emission was the same as before except that the intensity of the emitted sounds was measured only in the surrounding atmosphere, there being no opportunity to carry out underwater tests. The emitted sounds were picked up by a simple button microphone mounted on an arch, placed at a distance of 32 


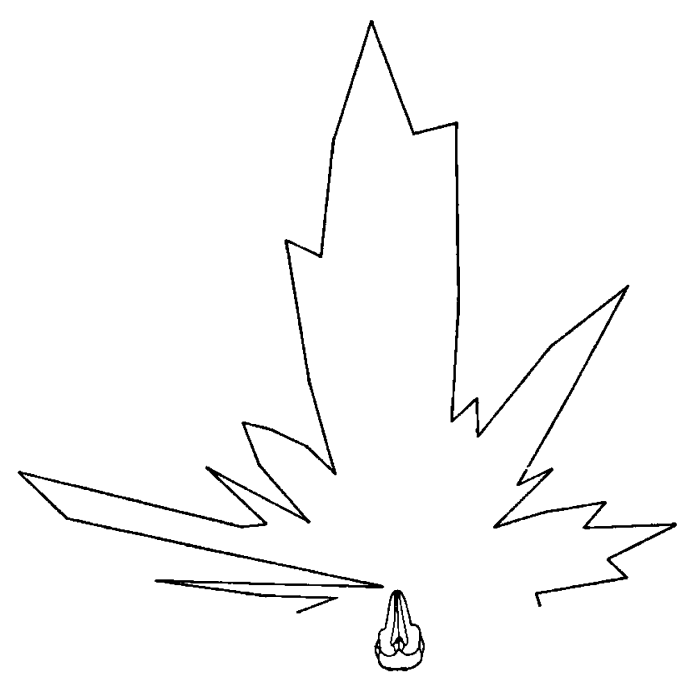

A

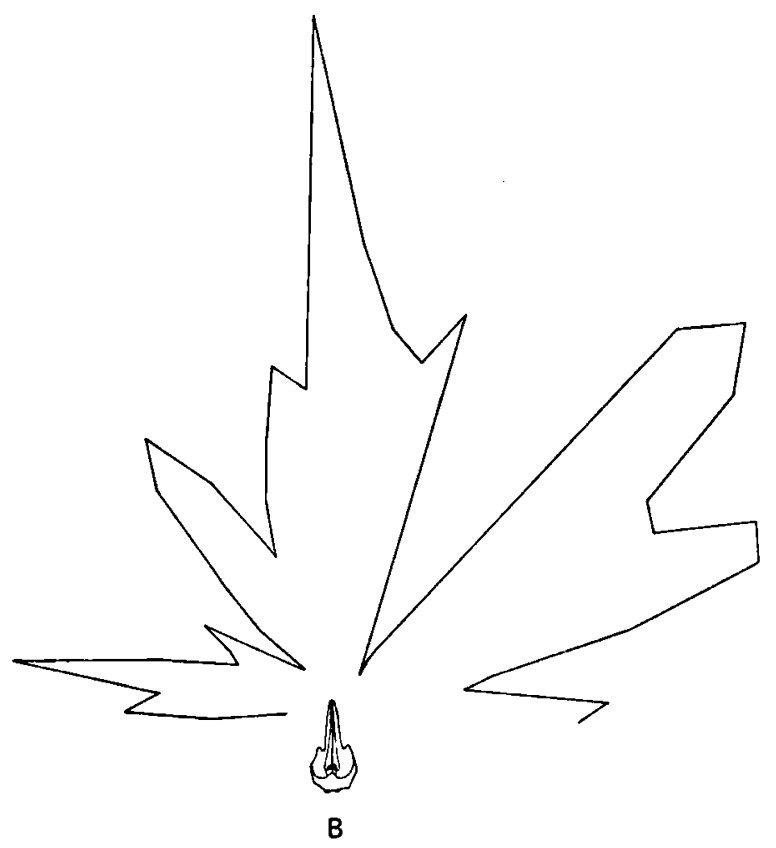

Fig. 12. Reconstruction of the sound field measurements in a horizontal plane, measured at a distance of $32 \mathrm{~cm}$ from the tip of the snout: A. of a Phocoena phocoena at a frequency of $1.2 \mathrm{kHz}$, B. of a Delphinus delphis at $1.8 \mathrm{kHz}$.

$\mathrm{cm}$ from the tip of the rostrum. Signals from the microphone were fed via an amplifier into an oscilloscope and a tube voltmeter. With this equipment it was possible to measure the intensity in both the horizontal and vertical planes, and thus to get an impression of the sound-field surrounding the rostrum. Since the sound-fields were directional it was evident that there must have been more than one emitting source. Reconstructions of the measured field are shown in figure 12. It may be concluded that in $P$. phocoena a well beamed sound pattern can be produced at low frequencies, whereas in the other species higher frequencies are necessary to result in directionality. Small differences in these frequencies can be correlated with the presence and the termination of the various secondary strands of dense bone in the margin of the maxillary bones.

\section{DISCUSSION}

From the anatomical review it would seem that a certain minimum amount of air stored in the upper respiratory tract is required. Some of this will be used for the selfsealing action of the blowhole and some of it will be subservient to phonation. It is clear that within the species, genera and families there is a considerable variation in the manner in which this air is stored. There is also variation in the number of diverticula involved in this process, and of course the volume of the air stored depends upon the hydrostatic pressure and therefore upon the depth at which the animal swims. The volume is greatest at the surface and becomes smaller as the animal dives. Thus these air chambers have to be capable of expansion and compression. From a cursory examination it would seem that the evolutionary trend is to shift the main storage spaces from the upper respiratory chambers to those immediately above the bony nares i.e. the premaxillary sacs. It will be seen that with the increasing degree of specialization of the species the premaxillary sacs become progressively larger in relation to those of the upper respiratory tract (fig. 13, 14, 15). In general terms it may be stated that the upper respiratory chambers are of older origin than the premaxillary sacs, which seem to have been a secondary development in the odontocetes.

Hyperoodontidae and Platanistidae, typical examples, have a very large vestibular-nasofrontal sac complex and relatively small premaxillary sacs. In Pontoporia, Inia, and Hyperoodon the anterior components of the nasofrontal sacs and 

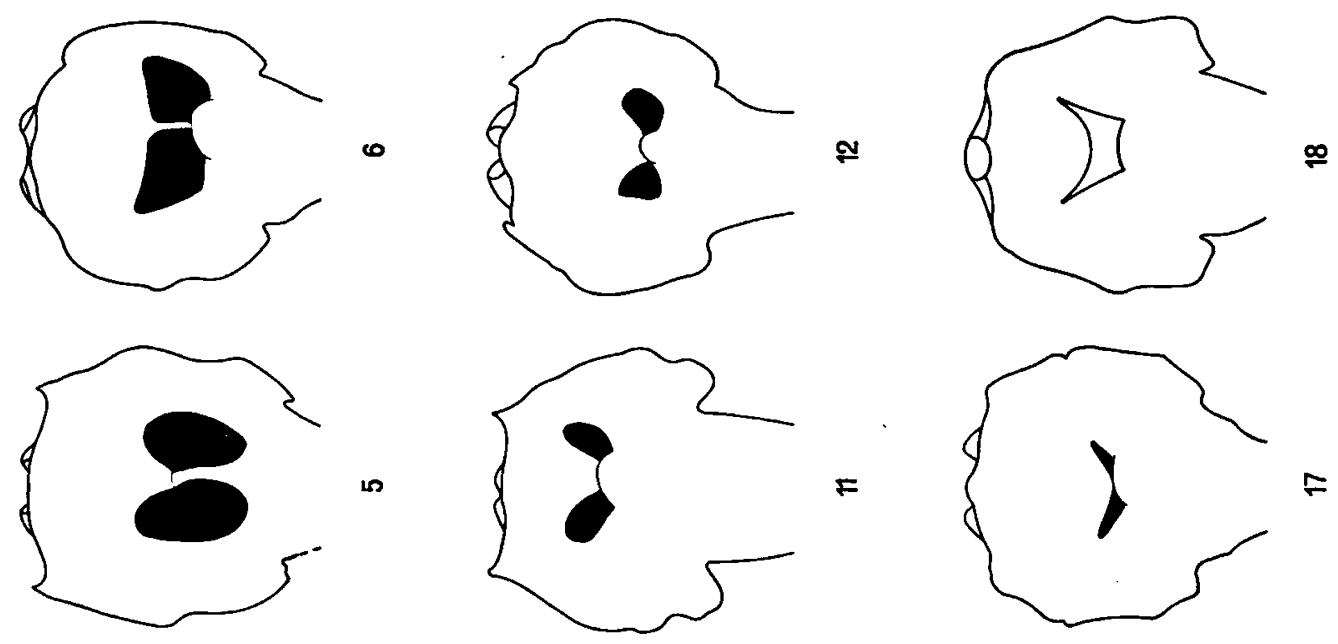

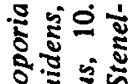

ปั

ㄷำ

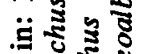

₹

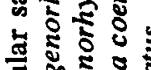

苨芯芯
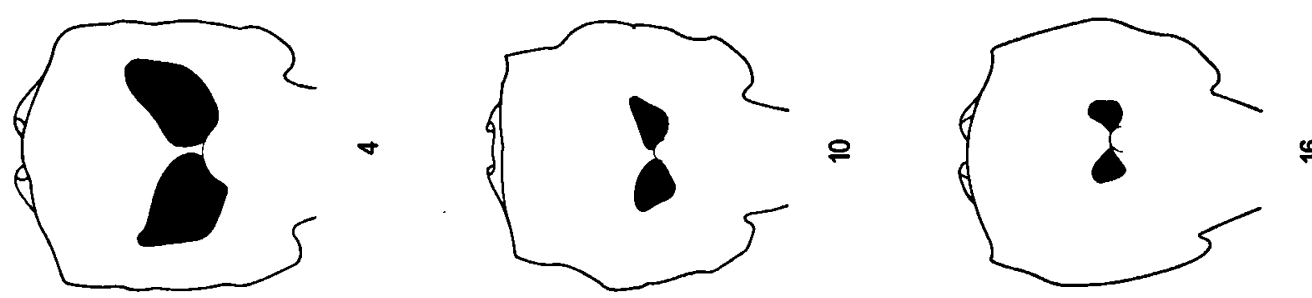

$\rightarrow n$ के

ป气

पूँ

รี

을

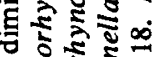

ป气

ब
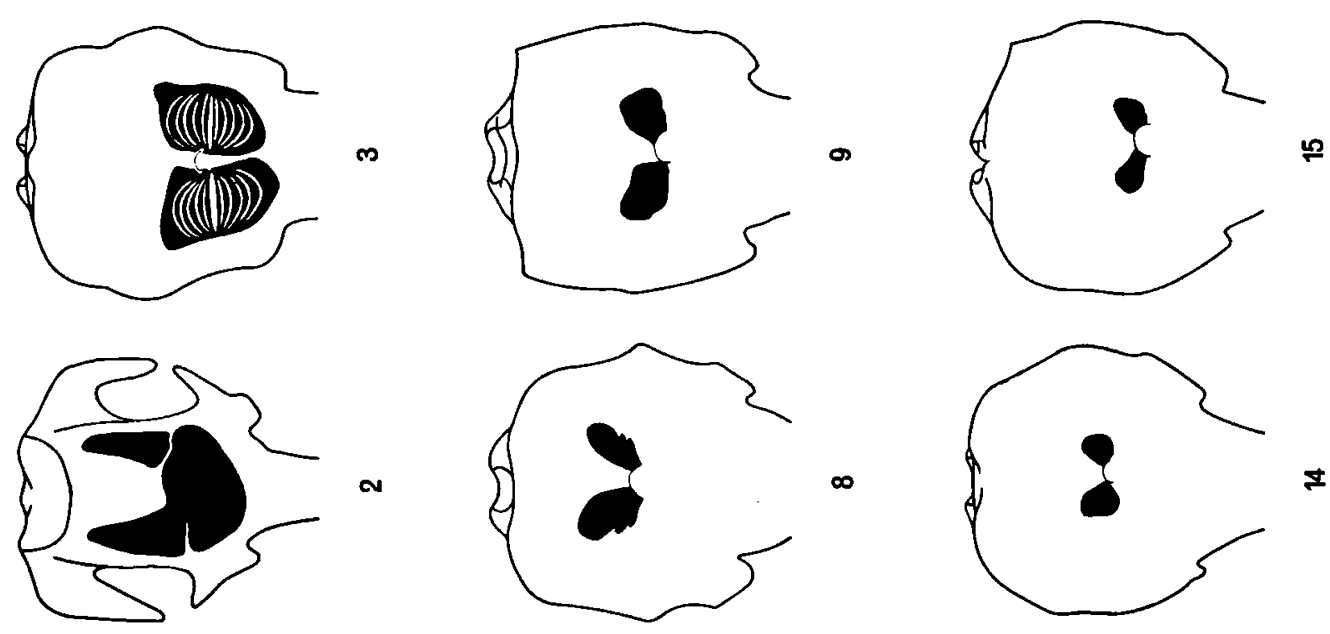

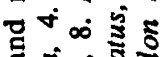

สิ

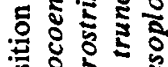

드 客

ક

$\infty$ 는

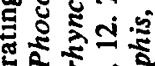
논

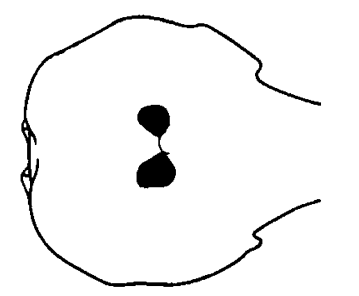

\%

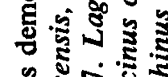

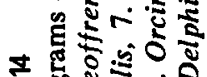

कo

我 0

4.50

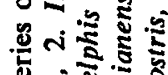

कू
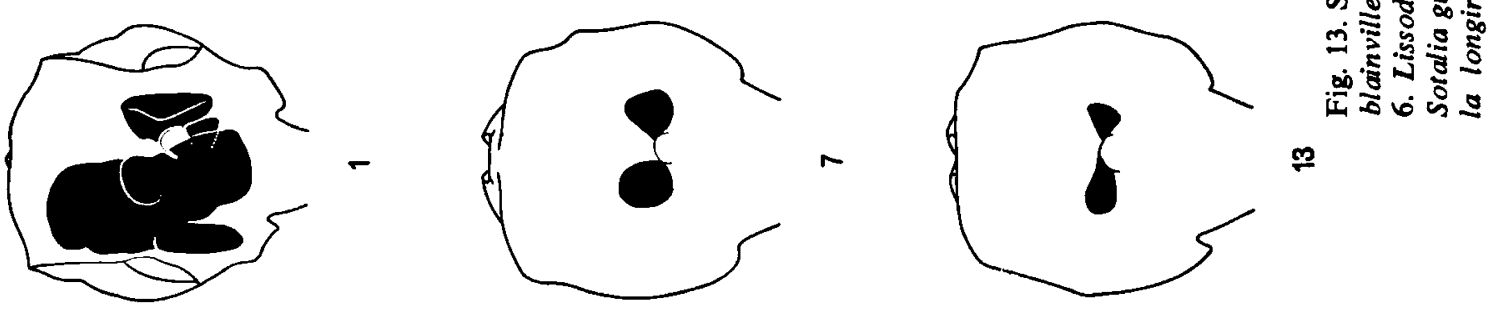
accessory sacs are absent. However, the former are present in Mesoplodon even though its general organization is similar to that of Hyperoodon. The Physeteridae show a considerable enlargement of the nasofrontal sac on the right side whilst that of the left is absent. A small premaxillary sac can be found on the left side in Kogia, but none are present in Physeter. In the Phocoenidae both anterior and posterior components of the nasofrontal sacs are proportionally very large, whilst the premaxillary sacs are small. Sometimes slight vestiges of accessory sacs are present. In Cephalorhynchus the rostral components of the nasofrontal sacs are larger than in Phocoena but the caudal sections are smaller. The premaxillary sacs, and also the accessory sacs, are considerably larger than in any of the species mentioned above.

In Lissodelphis the nasofrontal sacs are relatively smaller than in Cephalorhynchus although the anterior components are larger than the posterior components. Accessory sacs and premaxillary sacs are well developed. The genus Lagenorhynchus shows a gradation from $L$. albirostris through $L$. obliquidens, and $L$. acutus to $L$. obscurus, a series in which the nasofrontal sacs are proportionally very large in $\boldsymbol{L}$. albirostris and considerably reduced in $L$. obscurus. In all species, however, the posterior components of the nasofrontal sacs are very much reduced in comparison with the anterior components. Accessory sacs and premaxillary sacs are well developed, mostly so in $L$. obscurus.

This general evolutionary trend towards a greater development of the premaxillary sacs, with reduction of the nasofrontal complex and enlargement of the accessory sacs, is continued throughout the Delphinidae from Orcinus through Grampus, Tursiops and Stenella to Delphinus. In these latter genera the nasofrontal sacs became reduced to narrow tubes and with respect to Tursiops, were referred to as tubular sacs, by Lawrence \& Schevill (1956). The premaxillary sacs meanwhile became comparatively enlarged. Correlated with this diminution of the caudal section of the nasofrontal sacs, the accessory sacs became correspondingly larger. The size of the vestibular sacs also shows a trend towards reduction, with some notable exceptions which I consider to be secondary. For instance in Mesoplodon the vestibular sacs are apparently very small, and in Hyperoodon vestigial (fig. 13-18) but this is considered to be due to a secondary elon- gation of the nasal tract caused by the elevation of the supraoccipital crest in Mesoplodon and by additional elevation of the maxillary crests in Hyperoodon. Thereby the vestibular sacs are incorporated into a capacious vestibule. In Physeter the vestibular sacs, in common with all the other pneumatic diverticula of the left side, are absent. Noteworthy is the condition of the vestibular sac found in the Phocoenidae (see page 141).

Because of their alleged function in phonation it is necessary to pay attention to the structure of the nasal plugs throughoui the suborder (fig. 16). In the Platanistidae these consist of small antero-caudally elongated bulbs without lateral extensions (fig. 16, B). They are similarly formed, though much larger in the Hyperoodontidae (fig. $16, \mathrm{C})$. Due to the elevation of the supraoccipital region, in this family the plugs are orientated dorso-caudally rather than horizontally. There is a faint vestige of a lateral flap on the right nasal plug of Mesoplodon (fig. 16, D). The organization and modification of the nasal plugs of the Physeteridae have been dealt with at some length by Schenkkan \& Purves (1973).

At present it suffices to say that topographically they resemble in no way the condition found in other odontocetes. In Phocoena small liplike extensions appear on the lateral margin of the plugs (fig. 16, E). These extensions become progressively larger from Lagenorhynchus (fig. 16, F) to Stenella (fig. 16, G) and are shaped concaveconvex with the concavity uppermost.

Microscopic examination of the lining of all diverticula mentioned above shows that they are composed of stratified, keratinized, squamous epithelium like that of the external skin, although differing from this in the arrangement of the dermal papillae. There is no mucous membrane.

The modifications of the upper respiratory tract outlined above have taken place more or less asymmetrically, the degree of reduction being greater on the left than on the right side.

\section{The function of the nasal tract}

In order to gain an insight into the mechanism of the upper respiratory tract among the various species, it is necessary to form a clear idea of what happens immediately after the breathing or "loading up" phase. During this phase all the muscles of the blowhole are in a state of contraction, the air sacs are compressed, and the lumen of the 

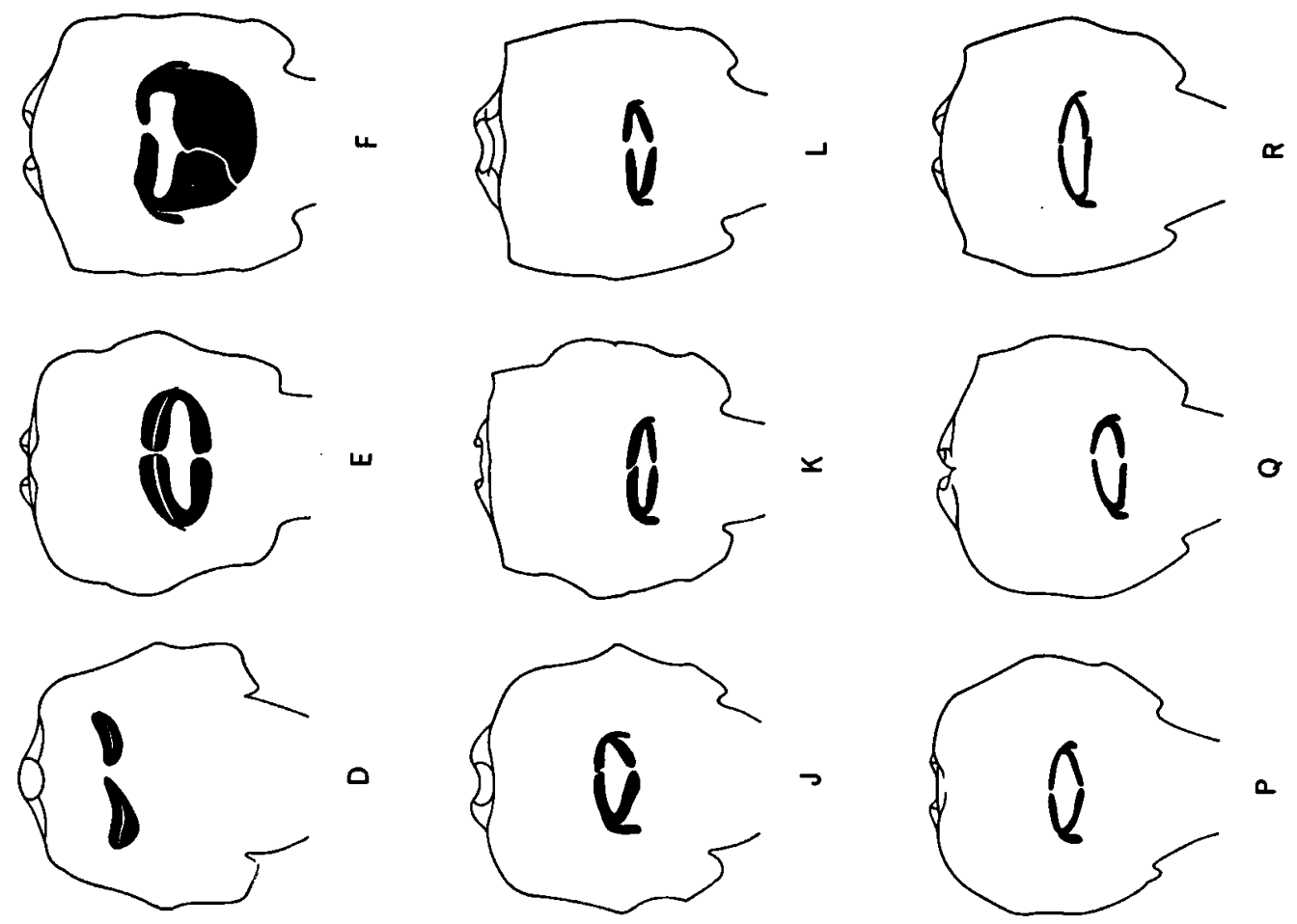

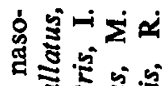

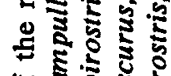
4.

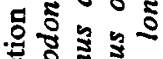
สำ

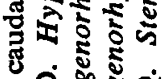

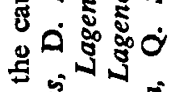

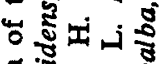
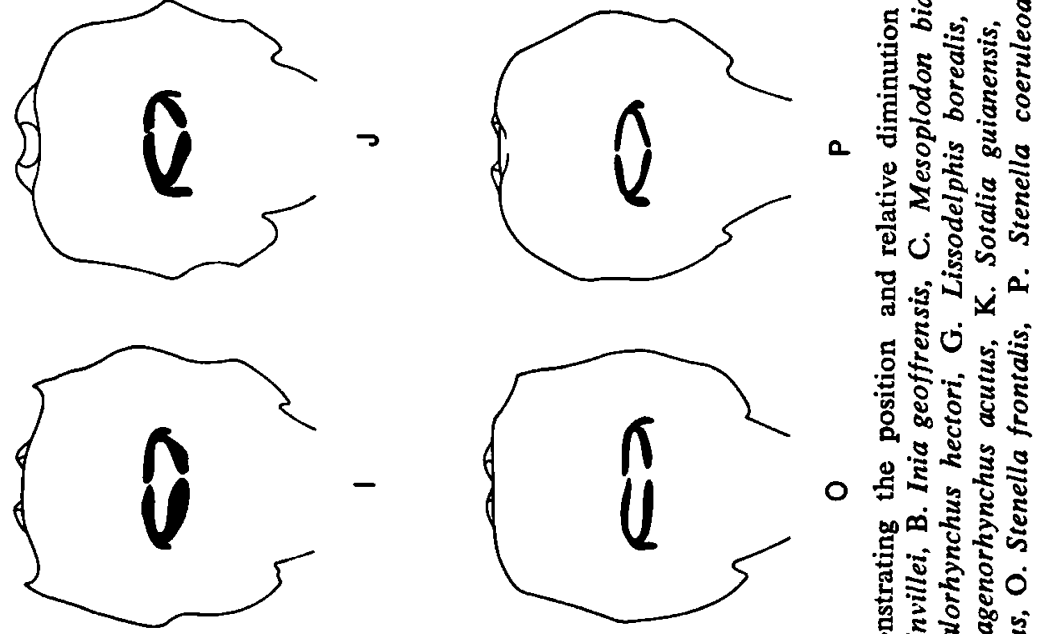
ริ
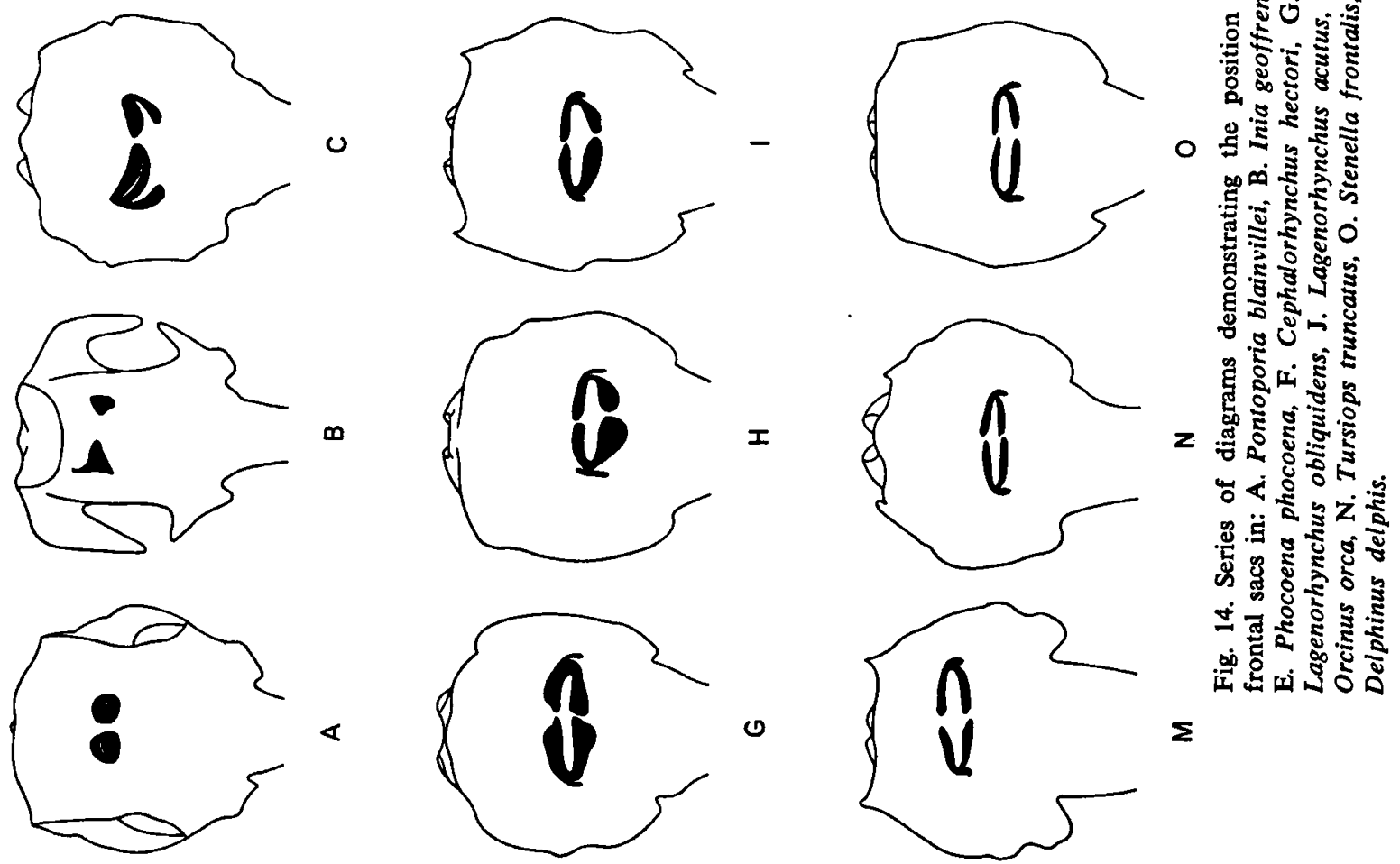


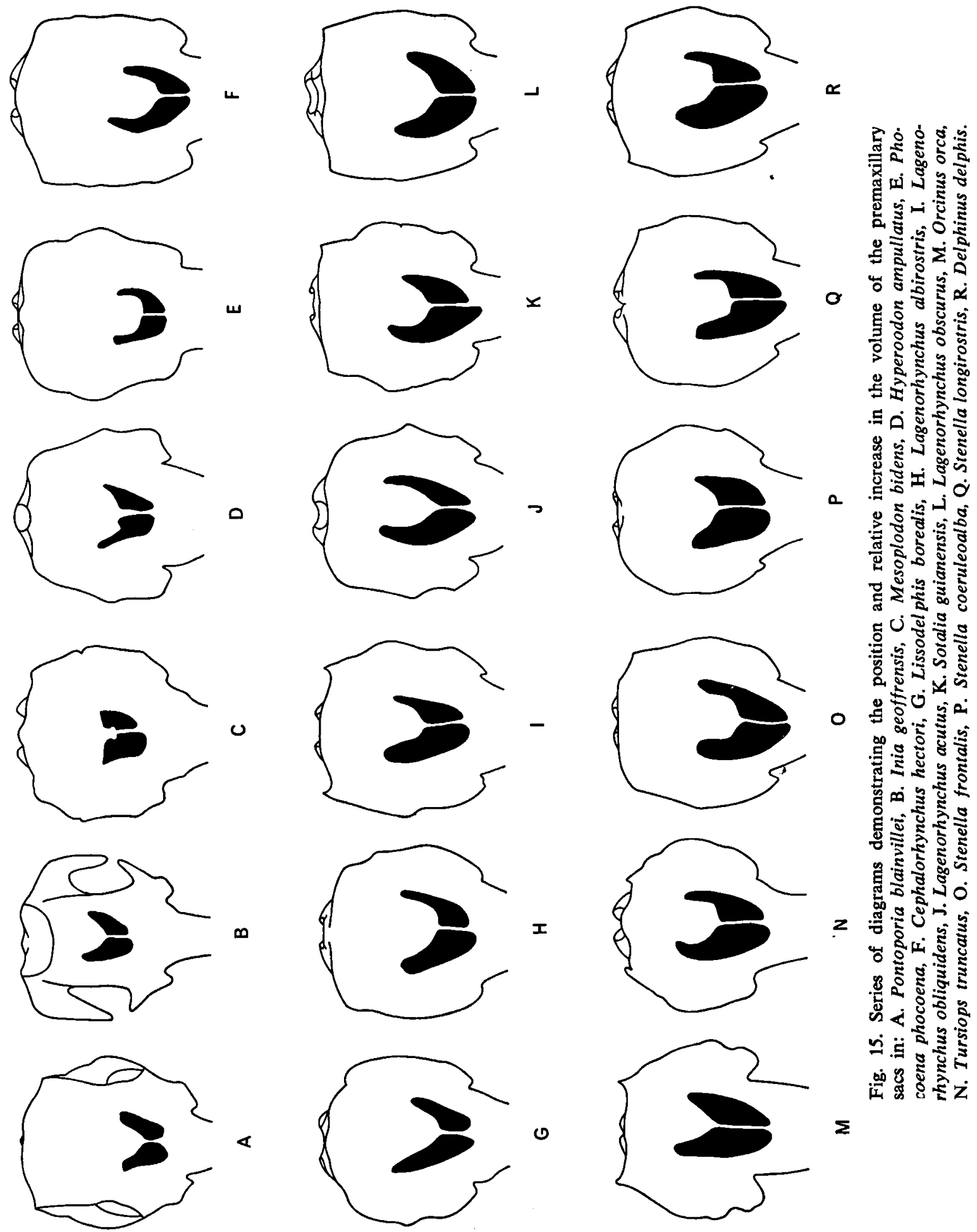




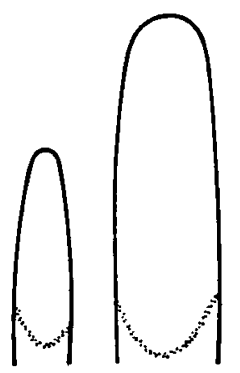

A

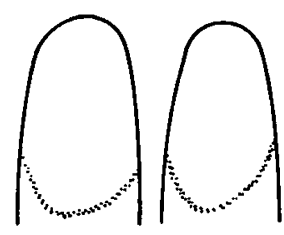

B

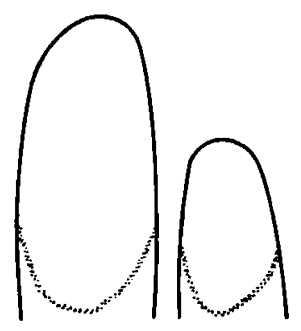

C

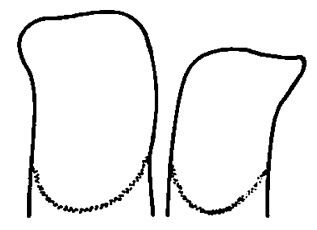

D

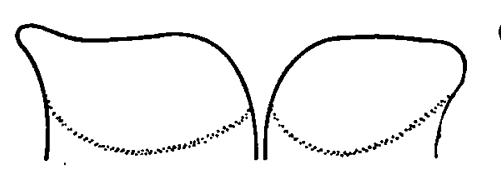

E

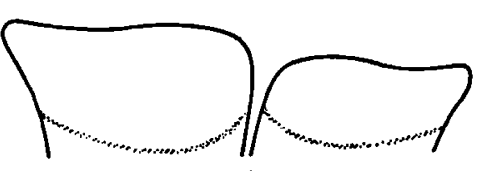

$\mathbf{F}$

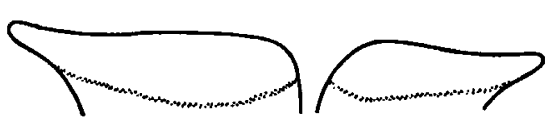

G

Fig. 16. Series of schematic diagrams demonstrating the development of the lateral flaps of the nasal plugs in: A. Kogia, B. Pontoporia, C. Hyperoodon, D. Mesoplodon, E. Phocoena, F. Lagenorhynchus, G. Stenella.

nares is wide open and therefore cannot be involved in phonation. After the "loading up" phase the nasal plugs become seated in the upper nares and the lips of the blowhole are closed by their own elasticity (cf. p. 129). In the Platanistidae and Hyperoodontidae any air subsequently blown through the trachea and glottis will pass upwards along the convex surfaces of the nasal plugs to the highest point of the respiratory tract, i.e., into the nasofrontal sacs. By this means the blowhole ligament is thrust forward until it is settled into the groove on the dorsal and lateral margins of the plugs. In this way the plugs will be prevented from moving upwards, and any further increment of air would pass through the narrow slits described on p. 136 into the premaxillary sacs (fig. 9). If air were drawn backwards to the nares, the premaxillary sacs would be emptied first, and the nasofrontal sacs subsequently.

The Hyperoodontidae are known to produce echolocation clicks, but so far no whistles have been recorded. According to the hypothesis of Norris et al. (1971) these clicks would be produced during the passing of air alongside the nasal plugs, which, it may be borne in mind, do not possess lateral flaps. This means that the entire nasal plug mass, which in a large Bottlenosed Whale may weigh up to $800 \mathrm{~g}$, would vi- brate with a recurrence frequency of up to 300 pulses per second. Inertia would make this impossible and therefore some other source of the sound must be looked for. The subject of phonation in the Physeteridae has been dealt with by Schenkkan \& Purves (1973).

In the Phocoenidae air flowing up the nasal passages will get into both the anterior and posterior components of the nasofrontal sacs and the blowhole ligament will be secured into the recess on the upper border of the nasal plugs as in the Hyperoodontidae. Subsequently, air will pass into the premaxillary sacs but as these are relatively small, the greater volume of air would be stored in the nasofrontal complex. Air drawn backwards through the air passages would empty successively the premaxillary sacs, the rostral, and the caudal section of the nasofrontal sacs. The progressive enlargement of the premaxillary sacs and the diminution of the volume of the nasofrontal complex during the phylogeny of the suborder, has made more and more of this shuttling air flow into the premaxillary sacs, the quantity entering the upper cavities being just sufficient to provide a pneumatic seal for the blowhole. As stated earlier there is a progressive phylogenetic enlargement of the lateral flaps of the nasal plugs whilst these acquire a concave-convex shape. In this condition air could 
pass upwards along their curved lateral aspects, but any suction force exerted from below or any pressure exerted from above would cause these flaps to be pressed against the smooth surface of the premaxillary bones so that they would act as one-way valves preventing the passage of air downwards. So in these more highly specialized odontocetes there is a mechanism constituting a permanent seal of the blowhole between the successive external respirations. This phenomenon can easily be demonstrated in the laboratory. If air is blown upward through the trachea of a recently died Delphinus delphis or other species, the blowhole actually seals itself and the current of air stops. Manual pressure exerted externally in this region cannot force the air backwards. Only air which is stored in the premaxillary sacs can be evacuated back through the posterior nares.

This mechanism implies that if the lateral flaps of the nasal plugs are used in the production of sonar clicks, as has been postulated, the air expended by sonar during submergence could not be recycled without interfering with the pneumatic seal of the blowhole. Consequently the capacity for producing sonar would soon be exhausted. Moreover the clicks, if really produced in this region, would be confined to the right side since the nasal plug flaps are poorly developed on the left. Norris et al. (1971) have advanced such a hypothesis indeed. It is difficult to see, how in these circumstances a beamed type of sound transmission could result, since all beamed transmissions, either of sonar or radar, are produced through interference between two or more identical sources operating coherently. Norris (1964) postulated that the beaming of the sound was due to reflection from the curved frontal aspect of the narial region which he likened to a parabolic mirror. Moreover, the sound would be focussed by the extensive adipose tissue on the forehead referred to as "melon" which, according to him, would act as an acoustic lens. A condition for the entry of the sound wave into this acoustic lens was that the initial sound transmission would be reflected from the frontal aspect of the skull to the vestibular and premaxillary sacs where it would be further reflected to converge on the melon. These reflections would be due to the presence of gas in the air sacs.

Since the vibrating source, according to Norris (loc. cit.) is located in the upper narial tract, sound emanations would be subject to multiple internal reflections from the walls of the nasal passages themselves and thus suffer an enormous loss of energy before passing either to the vestibular and premaxillary air sac systems or to the melon. Furthermore, if the melon has refractive properties, as Norris postulates, then its acoustic impedance must be considerably different from that of the muscles and the surrounding water. In this case there would be still more loss of energy due to reflection at the melon/water interface.

For reasons concerning the function of the upper respiratory tract stated above, it is supposed that in the higher odontocetes the entire phonatory air is stored in, and recycled from the premaxillary air sacs. There is fairly good evidence (Cadenat, 1959; Rancurel, 1964; Purves \& van Bree, 1972), that the Bottle-nosed Dolphin, Tursiops truncatus, is capable of making foodforaging dives to as much as 600 metres, in which case air from the premaxillary sacs must be compressed into the bony nares. It is apparent that under extreme pressure conditions only a minute amount of air is available for phonation. It was seen in the Physeteridae (Schenkkan \& Purves, 1973) under these conditions, that probably the whole of the narial air sac system is collapsed, all the air being compressed into the nasopharynx. This would seem to apply also to the Hyperoodontidae, since at least in Hyperoodon the maximum diving depth is known to be comparable with, or even to exceed, the performance of Physeter. Under these conditions the cavernous tissue in the upper bony nares described previously, would be expanded, leaving a very small residue of air in the posterior narial cavity. Under these circumstances it is difficult to see how phonation could occur anywhere but in the glottis. By operation of the omohyoid and thyrohyoid muscles sufficient air could be sucked into the larynx to produce the echolocation clicks that are required in sonar.

It is conceivable that the globular mass of adipose tissue above the right premaxillary sac in Mesoplodon subserves the same function as does the spermaceti organ in the Physeteridae, i.e. of producing slight negative pressure (due to its low specific gravity) in the right naris to assist the phonatory process.

There are several mechanical reasons for believing that the sonar emitter is located at the epiglottic spout:

1. The production of a train of relaxation os- 
cillations through a narrow, constricted aperture is very economical in the use of air.

2. It is well known that muscle operates at maximum efficiency when it is working against a "matched load". Such a matched load only occurs in the nasopharynx where the intrinsic muscles of the larynx have to compress air against the constriction of the palatopharyngeal sphincter. No such "matched load" occurs in the upper respiratory tract. The lateral flaps of the nasal plugs are non-muscular and if they were to vibrate at all, they would do so freely in an air cavity.

3. One of the most serious defects of early, mechanical echo-sounders was that they were not sufficiently "damped", i.e. the pulses had a long rise and decay time. This produced unwanted resonance and extraneous echoes which were difficult to separate from the main echoes. Pulses produced by the epiglottic spout of cetaceans are heavily damped by the relatively massive cuneiform and epiglottic cartilages which are unnecessarily rigid for mere respiration. However, the lumen between them can be widened for this function during breathing. Double pulses have often been recorded in trains of oscillations emitted by cetaceans, but recently, with more accurate apparatus, these have been found to be artefacts.

4. The arrangement of the laryngeal pouches and mucous folds is such that, when the epiglottic spout is constricted, compression of the laryngeal chamber by the thyoarytenoid muscles will only drive air upwards through the spout, the tracheal end being blocked by the blindly ending pouches.

5. One of the most important characteristics of the sonar apparatus in cetaceans would be the effective range of its low-frequency component, so it would be interesting to calculate approximately the range of a train of pulses in a typical odontocete such as Tursiops truncatus. The intrinsic musculature of the larynx of an adult North Atlantic Bottle-nosed Dolphin weighed 400 grams, and cetacean muscle is capable of a short burst of energy of 4-5 kg m sec per $\mathrm{kg}$ muscle (Gray, 1936), (Purves et al., in preparation). Taking the larger figure, this is equivalent to $20 \mathrm{~W}$ approximately for $400 \mathrm{~g}$ of muscle. A Fessenden echo sounder working at $50 \%$ efficiency and consuming $1 \mathrm{~kW}$ had a range of $32 \mathrm{~km}$ (Wood, 1930). If the two types of oscillators are com- parable at all, the larynx of Tursiops should be capable of producing pulses with a range of $640 \mathrm{~m}$ assuming a working efficiency of $50 \%$. It may be purely coincidental that, as previously stated, the North Atlantic Bottle-nosed Dolphin is capable of making dives up to about 600 metres. It is conceivable that for a dolphin it would be important to perceive the availability of food at this depth before it dives since respiratory requirements will limit the duration of such a dive to about 10 minutes.

\section{The function of the vestibular sacs}

The function of the vestibular sacs in the Odontoceti remains problematical but one important fact appears from the present research. It is clear that in phylogeny there has been gradual reduction in their size in proportion to that of the head and of the premaxillary sacs; the vestibular sacs being largest in the primitive River Dolphins and smallest in the highly specialized pelagic species. This could be an indication that they represent characters inherited from the cetacean land-ancestry thus justifying Murie's (1873) comparison of the whale airsac-system with the nasal passage cavities of the Saiga antelope. However, in the special case of the vestibular sacs of cetaceans there is much greater similarity between these and the vestibular sacs or "false nostrils" of the horse Equus caballus!

On the other hand, since bone seems to undergo evolutionary change more rapidly than soft tissue, these sacs may represent a modification of the soft nasal passage caused by progressive shortening of the bony nares from the condition found in a long-snouted animal. The wrinkling of the integument of the nose in certain breeds of shortsnouted domestic dogs may be cited as a parallel. The considerable size of the vestibular sacs in the primitive long-snouted River Dolphins seems to suggest such a possibility. In support of this hypothesis one may draw attention to the fact that wherever there has been s e c o n d a r y elongation of the soft nasal passages, due to the formation of maxillary crests such as in Platanista and Hyperoodon, the vestibular sacs are either vestigial or absent.

Lawrence \& Schevill (1956) assigned to these sacs the function of a water-trap and their close observation and cinematographic studies of the respiratory cycle in a live specimen of Tursiops 
truncatus seem to indicate that this is at least one of their functions. Purves (1966) stated that a jet of water under pressure, aimed directly at the closed blowhole in a severed head of a Steno bredanensis was seen to cause the vestibular sacs to expand. Anderson (cited in Purves, 1966) was of the opinion that in Phocoena the vestibular sacs acted as floatation devices to keep the blowhole above water whilst the animal was asleep. This was deduced from the fact that when the air was expressed from the sacs of a specimen, it died in a motionless condition as the head and indeed the entire animal sank beneath the surface. In general a living dolphin seems to be unable to open its blowhole unless the vestibular sacs have been previously expanded. If these for some reason cannot be inflated, the animal will suffocate.

In this connection an interesting observation was made by Lawrence \& Schevill (1956) on their living Tursiops. They found that whilst the nasal plugs were still in closing position, the pressure in the nasofrontal sacs caused a quantity of air to enter the vestibular sacs without any of this air escaping through the blowhole. When pressure was released, the air passed back into the nasofrontal sacs. When the experiment was repeated on the severed head of a freshly killed animal, they found that none of the expressed air passed downward through the nasal passages. Apart from the fact that these observations provide very strong evidence that the lateral flaps on the nasal plugs act as unidirectional valves indeed, they provide a clue to the possible main role of the vestibular sacs in the normal breathing cycle.

Lawrence \& Schevill (1956) have shown that, in the nasofrontal sacs, the air is often held under considerable pressure, $124 \mathrm{~cm}$ of mercury being the highest pressure recorded by them whilst the animal was at the surface, and it is very likely to be double this figure when the animal is submerged. It is possible that just before surfacing to breath, the posterior part of the nasofrontal sac is compressed by the maxillonasal muscle and the air expanded into the vestibular sacs, the nasal plugs meanwhile remaining in closing position in the nares. The air in the vestibular sacs would then provide a pneumatic cushion beneath the superficial fascia of the vestibular sections of the $\mathrm{m}$. maxillonasalis, facilitating the rapid opening of the blowhole at the surface or even slightly below it (the latter phenomenon has frequently been observed). The initial out-gush of air would prevent the ingress of water and in the event of water entering at the end of the phase, this would be trapped by the vestibular sacs. That sea water does frequently enter these sacs is evinced by the presence of small particles enclosed in the epithelial lining of the vestibular sacs of some species and by the presence of some parasitic isopods I found in Cephalorhynchus hectori (see Bowman, 1971) though these can have entered the nasal passage actively.

Frequently there is a change in the direction of traction of the vestibular layers of the maxillonasal muscle with increasing age, caused by the development of the supraoccipital crests to which the epaxial muscles of the spine are attached. When this occurs there is also a shift in the orientation of the vestibular sacs to a posterodorsal direction.

The function is rather more obscure in the River Dolphins in which bony crests develop along the lateral edges of the maxillary bones in addition to the supraoccipital crest. In these cases the vestibular sacs show an extensive lateral expansion as well as a postero-dorsal one. Perhaps in these species the sacs are primarily floatation devices or, since both the premaxillary and nasofrontal sacs are relatively small, they may act as air depots for the sonar activity.

\section{Conclusion}

Finally it is necessary to comment on a paper by Norris et al. (1971) in which cineradiographic observations were made on a Spinner Dolphin, Stenella longirostris, during the emission of a "squeal". They state:

"In simplest terms what happens is that the nasopharynx widens and elongates, drawing air down both bony nares from the air spaces within the porpoise's forehead. Then the nasal plugs close and the nasopharynx is quickly closed from behind by the foreward movement of the nasopalatine sphincter, the anterior larynx or epiglottic spout, and its associated muscles. This must have the effect of forcing air up into the bony nares and increasing its pressure. Then, quickly following this compressional phase, air is released into the premaxillary air sacs on top of the rostrum and below the nasal plugs. This is soon followed by 2-4 pulsations of the tissues around the left nasal plug in which metered volumes of air are forced upward into the spaces above the 
plug. It is this pulsation that is always concurrent with the production of brief chirps or squeals in our records. Then, following completetion of the pulsation, the nasopharynx opens again and air is drawn down from above again prior to beginning a new series."

It is noteworthy that these authors' experiments were carried out with the animal out of the water, and that no one has disputed that dolphins can produce sounds with their nasal passages when the head is above water. Moreover, the authors also suggest that the same mechanism is used for sonar (the right nasal passage being involved) during which the head must be submerged. However, there are several objections against this interpretation:

1. If air were drawn down into the nasopharynx with the nasal plugs unsealed, as the authors describe, the unidirectional valve-action of the plug-flaps described in this paper would be inoperative and there would be nothing to prevent water from being sucked into the nares and nasopharynx from which it could not be removed Lawrence \& Schevill, 1956).

2. Extensive forward movement of the "nasopalatine sphincter" during what is called compression phase (Norris et al. 1971), is not possible since the sphincter is intimately blended with the superior constrictor muscle which is attached to the basioccipital bone of the skull. Forward movement of the larynx can and does take place during normal breathing and due to the sinistrad distortion of its cartilages, the epiglottic spout moves towards the left naris which is the principle respiratory channel. In this position the epiglottic spout is freed from the constricting action of the palatopharyngeal sphincter and can be dilated by contraction of the interarytenoid muscle. Thus dilated it could not force air up to the bony nares.

3. The ensuing expansion of the premaxillary sac implies that during the compression phase these sacs are also compressed, presumably by the deeper layers of the maxillolabialis, otherwise they would expand simultaneously with the compression phase. It must be assumed that the premaxillary sacs are compressed for a second time so that air can be "metered" past the nasal plugs into the spaces above the plugs to produce the chirping sounds. Whilst it would be possible to retrieve this air by withdrawing the nasal plugs when the animal is out of the water, it would not be possible with the plugs remaining in situ as would occur under water (due to the unidirectional valve action) and this air would represent a complete loss from the echolocation reservoir.

In virtue of these considerations it must be concluded that at least in sonar the mechanism described by Norris et al. (1971) is not employed.

We have seen from this survey that during the course of evolution, the premaxillary sacs became progressively larger in proportion to the size of the head whilst the vestibular and nasofrontal sacs became smaller.

If sonar pulses are produced, as Norris et al. postulate, by "metering" air from the premaxillary sacs via the lateral flaps of the nasal plugs to the nasofrontal sacs, then we are confronted with the paradoxical situation that the greater the reservoir of air in the premaxillary sacs, the smaller is the receptacle which will eventually accommodate it. From the point of pulse-train duration and mechanical efficiency this appears incomprehensible.

If on the other hand we believe that only the small amount of air required for the pneumatic occlusion of the blowhole, is injected into the nasofrontal sacs, and that during phonation, air passes from the larynx into the premaxillary sacs and back again, then the evolutionary process in odontocetes becomes manifestly intelligible.

In the Mysticeti there are no nasal sacs of the type found in the Odontoceti and with their massive "muscular laryngeal pouches" these animals clearly phonate with the larynx. At suitable depths, these sounds apparently travel thousands of metres through the ocean and there is no reason to doubt that sonar in Odontoceti is also laryngeal in origin. 


\section{ACKNOWLEDGEMENTS}

Grateful acknowledgements are due to many persons and institutions who made it possible to carry out the present study.

This study was started in cooperation with drs. M. W. L. Groeneveld-Sitsen under the supervision of the late Prof. Dr. E. J. Slijper. I gratefully remember and acknowledge their contributions. The facilities and material provided in the Zoological Laboratory of the University of Amsterdam were generously continued by Prof. Dr. G. Barendrecht. He also showed keen interest in this subject. I likewise wish to thank the staff of the Zoological Laboratory, for enabling me to do all the work for this study.

Many thanks are due to the management of the Institute of Taxonomic Zoology (Zoologisch Museum) of the University of Amsterdam and especially to Dr. P. J. $\mathbf{H}$. van Bree, curator of mammals, for all the material provided and for his advice concerning the taxonomy.

I wish to mention in this respect also Mr. Frank D. Robson (New Zealand) for his efforts in coilecting and dispatching to the Institute of Taxonomic Zoology, a great number of deepfrozen specimens of dolphins.

I gratefully acknowledge the management of the Rijksmuseum van Natuurlijke Historie, Leiden and especially
Dr. D. C. Geyskes and Dr. A. M. Husson for providing material and facilities.

I am indebted to the Netherlands Institute for Fishery Investigations (R.I.V.O.) IJmuiden and to the Netherlands Institute for Sea Research (N.I.O.Z.) Texel, for material provided.

Thanks are due to the Dolfinarium at Harderwijk and especially to Dr. W. H. Dudok van Heel for material provided and possibilities to observe and study dolphins in his care.

I would like to thank the Trustees and the Keeper of Zoology of the British Museum (Natural History), London, for the facilities to study material in their museum.

Special thanks are due to Dr. P. E. Purves (British Museum, Natural History) and to Dr. W. L. van Utrecht (Zoological Laboratory, University of Amsterdam) for reading the manuscript and for all the valuable discussions and advice incorporated in the present study.

I gratefully acknowledge the financial aid I received from the Netherlands' Organization for the Advancement of Pure Research (Z.W.O.), which made my studies possible. This organization also subsidized my visits to the British Museum (Natural History), London.

\section{ABBREVIATIONS}

$\begin{array}{ll}\text { AP } & \text { adipose pad } \\ \text { BL } & \text { blowhole } \\ \text { CM } & \text { maxillary crest } \\ \text { CSM } & \text { supraoccipital crest } \\ \text { DM } & \text { diagonal membrane } \\ \text { GF } & \text { globular mass of fat } \\ \text { LB } & \text { blowhole ligament } \\ \text { LNP } & \text { nasal plug ligament } \\ \text { M } & \text { maxillary bone } \\ \text { ML } & \text { melon } \\ \text { MM } & \text { m. multifidus } \\ \text { MNP } & \text { nasal plug muscle } \\ \text { MS } & \text { "museau de singe" }\end{array}$

$\begin{array}{ll}\text { MXL } & \text { m. maxillolabialis } \\ \text { MXN } & \text { m. maxillonasalis } \\ \text { NC } & \text { nasal canal } \\ \text { NPC } & \text { nasopalatine canal } \\ \text { PM } & \text { premaxillary bone } \\ \text { SA } & \text { accessory sac } \\ \text { SN } & \text { nasofrontal sac } \\ \text { SNC } & \text { caudal section of nasofrontal sac } \\ \text { SNR } & \text { right nasofrontal sac } \\ \text { SPM } & \text { premaxillary sac } \\ \text { SV } & \text { vestibular sac } \\ \text { SVR } & \text { right vestibular sac } \\ \text { V } & \text { vestibule }\end{array}$

\section{REFERENCES}

Aristotle, 1910. The works of Aristotle. IV. Historia animalium, translated by D'Arcy Wentworth Thompson: $i-x v, 486 a-633 b$, $i-x x x$. (Oxford University Press, Oxford).

BenhaM, W. B., 1901. On the anatomy of Cogia breviceps. Proc. zool. Soc. Lond., 1901 (2) : 107-134, pls. VIII-XI,text figs. 7-8.

Boenninghaus, G., 1902. Der Rachen von Phocoena communis Less. Eine biologische Studie. Zool. Jb., 5 (17) : $1-98,1 \mathrm{pl}$.

Bowman, T. E., 1971. Cirolana narica n. sp., a New Zealand isopod (Crustacea) found in the nasal tract of the dolphin Cephalorhynchus hectori. Beaufortia, 19 (252) : 107-112.

[BURNE, R. H.], 1952. Handbook of cetacean dissections : 1-70. (Trustees Brit. Mus., London).
Cadenat, J., 1959. Notes sur les Delphinidés ouestafricains. VI. Le gros Dauphin gris (Tursiops truncatus) est-il capable de faire des plongées profondes? Bull. I.F.A.N., (A) 21 (3) : 1137-1141, 2 pls.

Caldwell, M. G., D. K. Caldwell \& W. E. Evans, 1966. Preliminary results of studies on the sounds and associated behavior of captive amazon freshwater dolphins, Inia geoffrensis. Proc. Ann. Conf. Biol. Sonar, 3 : 178-185.

Caldwell, D. K., J. H. Prescott \& M. C. Caldwell, 1966. Production of pulsed sounds by the Pigmy Sperm Whale Kogia breviceps. Bull. Sth. Calif. Acad. Sci., 65 (4) : $245-248$.

DanoIS, ED. LE, 1911. Description d'un embryon de Grampus griseus Gray, Archs. Zool. exp. gén., (5) 8 : $399-420,2$ pls. 
Dawbin, W. H., 1967. Whaling in New Zealand Waters. Encycl. N.Z.: 3-7. (only seen as a reprint).

Diercks, K. T., R. T. Trochta, C. F. Greenlaw \& W. E. EvaNS, 1971. Recording and analysis of dolphin echolocation signals. J. acoust. Soc. Am. 49 (6) : $1729-1732$.

DijkgraAF, S., 1943. Over een merkwaardige functie van den gehoorzin bij vleermuizen. Versl. gewone Vergad. Afd. Natuurk. K. ned. Akad., 52 : 622-627.

- , 1947. Het oriëntatievermogen bij vleermuizen. Vakbl. Biol. 27 (7) : 97-103.

Dudok van Heel, W. H., 1962. Sound and Cetacea. Neth. J. Sea Res., 1 (4) : 407-508.

EberhardT, R. L. \& W. E. Evans, 1962. Sound activity of the California Gray Whale, Eschrichtius Glaucus. Audio Engng., 10 (4) : 324-328.

Evans, W. E. \& J. H. Prescotr, 1962. Observations of the sound production capabilities of the Bottlenose Porpoise : A study of whistles and clicks. Zoologica, N.Y., $47: 121-128$.

Evans, W. E., W. W. Sutherland \& R. G. Beil, 1964. The directional characteristics of delphinid sounds. In : W. N. TAvolga ed., Marine bio-acoustics : 353372. (Pergamon Press, Oxford, London, New York, Paris).

FrASER, F. C., 1947. Sound emitted by dolphins. Nature, $160: 759$.

Fraser, F. C. \& P. E. Purves, 1954. Hearing in cetaceans. Bull. Br. Mus. nat. Hist. (Zool.), 2 (5) : 101114. 2 pls.

,- 1960 . Hearing in cetaceans. Evolution of the accessory air sacs and the structure and function of the outer and middle ear in recent cetaceans. Bull. Br. Mus. nat. Hist. (Zool.), 7 (1) : 1-140.

GrAY, J., 1936. Studies in animal locomotion, VI. The propulsive powers of the dolphin. J. exp. Biol., 13 : 192-199, 3 figs.

GriffiN, D. R., 1946. Supersonic cries of bats. Nature, $158: 46-48$.

,- 1946 . The mechanism by which bats produce supersonic sounds. Anat. Rec., 96 : 519.

,- 1950 . Measurements of the ultrasonic cries of bats. J. acoust. Soc. Am., 22 : 247-255.

GrIfFIN, D. R., 1958. Listening in the dark. The acoustic orientation of bats and men : $1-413$. (Yale University Press, New Haven).

Griffin, D. R. \& R. Calambos, 1940. Obstacle avoidance by flying bats. Anat. Rec., 78 : 194-195.

GruHL, K., 1911. Beiträge zur Anatomie und Physiologie der Cetaceennase. Jena. Z. Naturw. (N.F.), 47 (3) : $367-414$.

HANKE, H. 1914. Die Nase von Mesoplodon bidens. In : W. KüKENTHAL : Untersuchungen an Walen, 2. Jena. Z. Naturw. (N.F.), 51 (1): 112-122, 6 pls.

Huber, E., 1930. Evolution of facial musculature and cutaneous field of Trigeminus. Q. Rev. Biol., 5 (2) : $133-187,389-437,46$ figs.

-, 1934. Anatomical notes on Pinnipedia and Cotacea. Publs. Carnegie Instn., 447 : 107-135.

HUNTER, J., 1787. Observations on the structure and oeconomy of whales. Phil. Trans. R. Soc., 77 (38) : 371-450, Pls. XVI-XXIII.

KellogG, W. N. \& R. Kohler, 1952. Reactions of the porpoise to ultrasonic frequencies. Science. 116 : $250-252$.
KellogG, W. N., R. Kohler \& H. N. Morris, 1953. Porpoise sounds as sonar signals. Science, 117 : $239-243$.

KernaN, J. D. JR. \& H. von W. Schulte, 1918. Memoranda upon the anatomy of the respiratory tract, foregut, and thoracic viscera of a foetal Kogia breviceps. Bull. Am. Mus. nat. Hist., 38 : 231-267, 16 figs.

KüKENTHAL, W., 1893. Vergleichend-anatomische und entwickelungsgeschichtliche Untersuchungen an Walthieren: Bau und Entwickelung der Cetaceennase. Denkschr. med.-naturw. Ges. Jena, 3 (2) : 322-349, 4 pls.

LAWrenCe, B. \& W. E. SChevill, 1956. The functional anatomy of the delphinid nose. Bull. Mus. comp. Zool. Harv., 114 : 103-151.

MCBRIDE, A. F., 1956. Evidence for echolocation by cetaceans. Deep-Sea Res., 3 : 153-154.

Mizue, K., M. Nishiwaki \& A. Takemura, 1971. The underwater sound of Ganges River Dolphins (Platanista gangetica). Scient. Rep. Whales Res. Inst. Tokyo, 23 : $123-128$.

Mizue, K., A. Takemura \& K. Nakasai, 1968. Underwater sound of the Chinese Finless Porpoise caught in the Japanese coastal sea. Studies on the little toothed whales in the West Sea area of Kyushu, XV. Bull. Fac. Fish. Nagasaki Univ., 25 : 25-32.

,- 1969 . Underwater sound of the False Killer Whale. Studies on the little toothed whales in the West Sea area of Kyushu, XVI. Bull. Fac. Fish. Nagasaki Univ., 28 : $19-29$.

MURIE, J., 1870a. Notes on the White-beaked Bottlenose, Lagenorhynchus albirostris, Gray. J. Linn. Soc. (Zool.), 11: $141-153$, pl. V.

-, 1870b. On Risso's grampus, G. rissoanus (Desm.). J. Anat. Physiol. Lond., 5 : 118-138.

,- 1873 . On the organization of the Caaing Whale, Globicephalus melas. Trans. zool. Soc. Lond., 8 : 235301, pls. XXX-XXXVIII.

NorRis, K. S., 1964. Some problems of echolocation in cetaceans. In : W. N. TAvolgA ed.: Marine bioacoustics : 317-336. (Pergamon Press, Oxford, London, New York, Paris).

,- 1969 . The echolocation of marine mammals. In : H. T. ANDERSEN ed.: The biology of marine mammals : 391-423. (Academic Press, New York/London).

Norris, K. S., K. J. Dormer, J. PegG \& G. J. Liese, 1971. The mechanism of sound production and air recycling in porpoises: a preliminary report. Proc. Ann. Conf. Biol. Sonar, $8: 1-11,4$ pls.

Norris, K. S., J. H. Prescott, P. V. Asa-Dorian \& P. PERKINS, 1961. An experimental demonstration of echo-location behaviour in the porpoise, Tursiops truncatus (Montagu). Biol. Bull., 120: 163-176.

Pierce, G. W. \& D. R. Griffin, 1938. Experimental determination of supersonic notes emittid by bats. J. Mammal., 19 : $454-455$.

Purves, P. E. 1966. Anatomical and experimental observations in the cetacean sonar system. In : $\mathbf{R}$. G. BUSNEl ed.: Systèmes Sonars Animaux; Biologie et Bionique : 197-270. (Symp. Frascati).

Purves, P. E. \& P. J. H. VAN BREe, 1972. Evolution and the pathology of deep diving in the Bottle-nosed Dolphin, Tursiops truncatus (Montagu, 1821) (Notes 
on Cetacea, Delphinoidea V). Beaufortia, 20 (260): 15-21.

Purves, P. E., A. Jonk \& W. H. Dudok van Heel, Locomotion in cetaceans. (in preparation).

RanCUREL, P., 1964. Note sur la plongée profonde de Tursiops truncatus. Cahiers O.R.S.T.O.M. (Océanogr.), 2 (4) : 135-141.

Raven, H. C. \& W. K. Gregory, 1933. The spermaceti organ and nasal passages of the Sperm Whale (Physeter catodon) and other odontocetes. Am. Mus. Novit., 677 : 1-18, 9 figs.

RAwitz, B., 1900. Die Anatomie des Kehlkopfes und der Nase von Phocaena communis Cuv. Int. Mschr. Anat. Physiol., 17 : 345-354.

SCHENKKAN, E. J., 1971. The occurrence and position of the "connecting sac" in the nasal tract complex of small odontocetes (Mammalia, Cetacea). Beaufortia, 19 (246) : $37-43,3$ figs.

,- 1972 . On the nasal tract complex of Pontoporia blainvillei (Gervais \& d'Orbigny, 1844) (Mammalia, Odontoceti). Invest. Cetacea, 4:83-90.

SchenkKan, E. J. \& P. E. Purves, 1973. The comparative anatomy of the nasal tract and the function of the spermaceti organ in the Physeteridae (Mammalia, Odontoceti). Bijdr. Dierk., 43 (1) : 93-112.

Schevill, W. E., R. H. BACKuS \& J. B. Hersey, 1962. Sound production by marine animals. In : M. N. HILL ed.: The sea. Ideas and observations on progress in the study of the seas, I : 540-566. (John Wiley \& Sons, New York/London).

SChevill, W. E. \& B. LAWRENCE, 1953. Auditory response of a Bottlenosed Porpoise, Tursiops truncatus to frequencies above $100 \mathrm{KC}$. J. exp. Zool., 124 (1) : $147-165$.

-, 1953. High-frequency auditory responses of a Bottlenosed Porpoise, Tursiops truncatus (Montagu). J. acoust. Soc. Am., 25 (5) : 1016-1017.

Schevill, W. E. \& W. A. Watkins, 1962. Whale and porpoise voices. A phonograph record. Woods Hole oceanogr. Instn. Contr., 1320 : $1-24$.

Tyson, E., 1680. Phocoena, or the anatomy of a porpess, dissected at Gresham College London. Dubl. phil. J., 2 (3) : 48-60.

VinCENT, F., 1959. Resultats sommaires concernant une étude préliminaire des émissions acoustiques de Delphinus delphis L. Bull. Soc. zool. Fr., 84 : 52-54.

-, 1960. Etudes préliminaires de certaines émissions acoustiques de Delphinus delphis $\mathbf{L}$. en captivité. Bull. Inst. océanogr. Monaco, [57] (1172) : 1-23.

WAtKINS, W. A., 1966. Listening to cetaceans. In : K. S. Norris ed.: Whales, dolphins, and porpoises : 471476. (University of California Press, Berkeley/Los Angeles).

WooD, A. B., 1930. A textbook on sound : 1-519. (G. Bell \& Sons, London). 